\title{
The evolution of the materials used
} in the yun technique for the decoration of Burmese objects: lacquer, binding media and pigments

Diego Tamburini ${ }^{1 *} \mathbb{B}$, Verena Kotonski ${ }^{2}$, Anna Lluveras-Tenorio ${ }^{3}$, Maria Perla Colombini $^{3}$ and Alexandra Green ${ }^{4}$

\begin{abstract}
A series of Burmese lacquered objects decorated with the yun (incised) technique and belonging to the British Museum's collection was analysed with the aim to investigate the decorative materials_lacquer, binding media, additives and pigments - used in the production of these objects, which span chronologically from the eighteenth century to the late twentieth century. As the manufacturing process is supposed to have remained very similar over this time period, especially regarding the use of materials, we were interested in scientifically assessing for the first time the nature of these materials and the correspondence to the written sources in the relation to their specific use. Gas chromatography mass spectrometry (GC-MS) and analytical pyrolysis with in situ silylation coupled with GC-MS (Py(HMDS)GC-MS) were used for the identification of the organic components in several samples taken from the coloured areas of the objects. Fibre optic reflectance (FORS) and Raman spectroscopies were used to identify the pigments after a visual investigation of the samples by digital microscopy. Burmese lacquer was detected in all objects and trends in its degradation were highlighted. Lipids, proteins and saccharide material were found to be mixed with lacquer, and they appeared to be applied with specific pigments, in good agreement with the written records, apart from proteins, which are not mentioned. The use of synthetic pigments, such as phthalocyanines blue and green and chrome yellow, was assessed in the most recent objects, showing an evolution in the use of pigments. Indigo, although expected, was not identified in any of the green samples and Prussian blue appeared to be the main source of blue colour. All this information is of fundamental importance for conservation practices and corrects the general opinion about the production materials of these objects. These results also open the way to future research dedicated to exploring the chemical interaction between Burmese lacquer, proteins, lipids, gums and pigments, with the aim to predict possible differences in degradation pathways.
\end{abstract}

Keywords: Burmese lacquer, Binding media, Pigments, Yun technique, GC-MS, Analytical pyrolysis, Raman spectroscopy, Conservation

\footnotetext{
*Correspondence: DTamburini@britishmuseum.org

${ }^{1}$ Department of Scientific Research, The British Museum, Great Russell

Street, London WC1B 3DG, UK

Full list of author information is available at the end of the article
}

SpringerOpen

(c) The Author(s) 2019. This article is distributed under the terms of the Creative Commons Attribution 4.0 International License (http://creativecommons.org/licenses/by/4.0/), which permits unrestricted use, distribution, and reproduction in any medium, provided you give appropriate credit to the original author(s) and the source, provide a link to the Creative Commons license, and indicate if changes were made. The Creative Commons Public Domain Dedication waiver (http://creativecommons.org/ publicdomain/zero/1.0/) applies to the data made available in this article, unless otherwise stated. 


\section{Introduction}

Burmese $^{1}$ lacquer (thitsi) has probably been used for more than a millennium, but no archaeological evidence is available before the thirteenth century, possibly due to the limited archaeological work undertaken in Myanmar in the last 60 years [1]. Damaged objects were also discarded and replaced in Burmese traditional practices, due to the belief that old and defective objects may bring bad luck. As a consequence, many Burmese lacquered objects in European collections date to the nineteenth to twentieth centuries and are mainly vessels that have been used domestically in private homes or in monasteries $[2$, 3].

Most information about the techniques of lacquer production is also relatively recent and starts with the British colonial period [1]. Burmese lacquer is obtained from the sap of the Melanorrhoea (Gluta) usitata tree, which belongs to the Anacardiaceae family and grows in Laos, Myanmar, Thailand and Cambodia. The sap is harvested from the tree by tapping and has a straw colour, which quickly turns glossy black. Its main function is to waterproof and heatproof the object and has excellent adhesive properties, as well as good stability in hot, acid and alkaline conditions. It is therefore a good binding medium for pigments and it has been applied to a variety of inorganic (metal and ceramic) and organic (wood, cane, palm-leaf, leather) substrates [1]. Nowadays, most containers, such as vessels, bowls and cups, are made of split coiled bamboo, but other wood substrates and basketry have also been used in the past.

A number of different decorative techniques are known across Myanmar, with the yun (incised) technique traditionally being the most common one. The term yun refers to a form of decoration where a surface is engraved and the grooves filled with colour, but $y u n$ is also used as the generic term for lacquer in Myanmar [4]. A small number of first-hand accounts of local craft practices are available describing this technique in some detail $[1,4-6]$. A comparison of these accounts, collected by researchers travelling to Myanmar, is summarised in Table 1. This reveals that materials and manufacturing processes remained similar over the period from the late nineteenth to twenty first centuries, which is a testament to a continuous tradition of craftsmanship. Any decorative layers require a smooth substrate, which is achieved by applying a paste called thayo to fill any interstices the work piece might show. Thayo paste consists of lacquer mixed with fillers,

\footnotetext{
${ }^{1}$ The authors are aware that since 1989 Burma is officially called Republic of the Union of Myanmar, but amongst researchers the term "Burma/Burmese" is still intrinsically linked with this type of lacquerware. We therefore decided to use "Burmese" as an adjective and "Myanmar" to refer to the state.
}

varying from coarse particles (e.g. sawdust ash) for the initial layers to fine particles (e.g. cow bone or cow dung ash) for layers closer to the decorative surface. The thayo ground is then covered with a series of 5-20 lacquer coatings without filler. The number of thayo and lacquer applications, the drying time between each application and the care taken smoothing the layers before a new layer is applied determine the quality of the finished object. Items earmarked for engraving are often of black or red colour, which will later show as the background colour after engraving. The yun technique relies on the principle that the colour will adhere only to the incisions of the engravings according to the dictates of the design and can be removed from non-engraved areas. Multi-coloured designs require repeated applications of differently coloured coatings. Different methods of applying the colour have been reported: the pigment is either mixed with a binder to form a paste and this paste is rubbed into the grooves, or the grooves are filled with binding media and the dry pigment in rubbed into still moist binder [6]. To avoid contamination of previously applied colours with the yet to be applied colour, any excess binder or pigment paste is wiped off immediately before it sets on the surface. Alternatively, a "barrier layer", consisting of water-soluble gum extracted from the neem/tama tree (Azadirachta indica) or the acacia tree (Acacia farnesiana), is applied and engraved. The colour is then applied and, once dried, the excess colour and the barrier layer are removed before the process is repeated for another colour. After each application of a layer, the object is mounted on a lathe and layers are smoothed by polishing the surface with an abrasive (pumice stone, sandstone, textile rag, rice husks, fossilised wood) in combination with water.

Most commonly the colours red, green and yellow and occasionally blue are found on yun lacquerware. Red colour is said to be based on cinnabar/vermillion (mercuric sulfide-HgS), referred to as hinthabada, or the cheaper red ochre (iron oxides) for lesser quality items. Green (atsein) is reported to be a mixture of orpiment (arsenic trisulfide- $-\mathrm{As}_{2} \mathrm{~S}_{3}$ ) and indigo. Yellow (saydan) is composed of pure orpiment, and orange is a mixture of orpiment and cinnabar/vermillion. The binding medium for all colours appears to be lacquer, with some addition of tung (shan-zi), peanut or sesame oil. Vegetable gums are not explicitly reported as a binder, but mainly as ingredients of the "barrier layer" between two colours (Table 1) $[1,4-6]$.

It appears from this description that lacquer is not the only organic material used for producing these objects and the written descriptions are somewhat hazy when it comes to the actual nature of the other materials used as binding media. Previous works have identified 

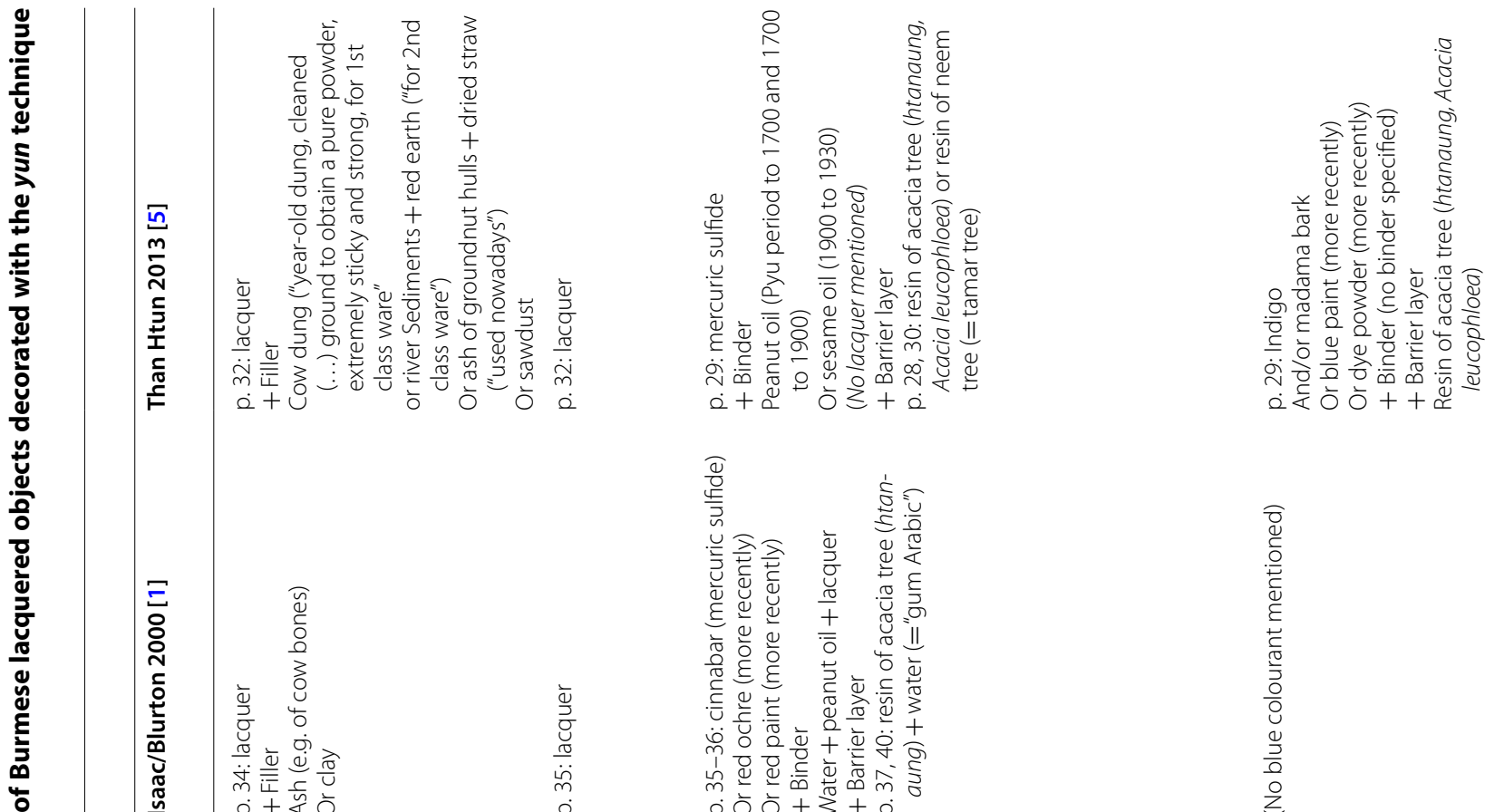

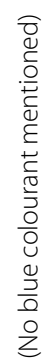
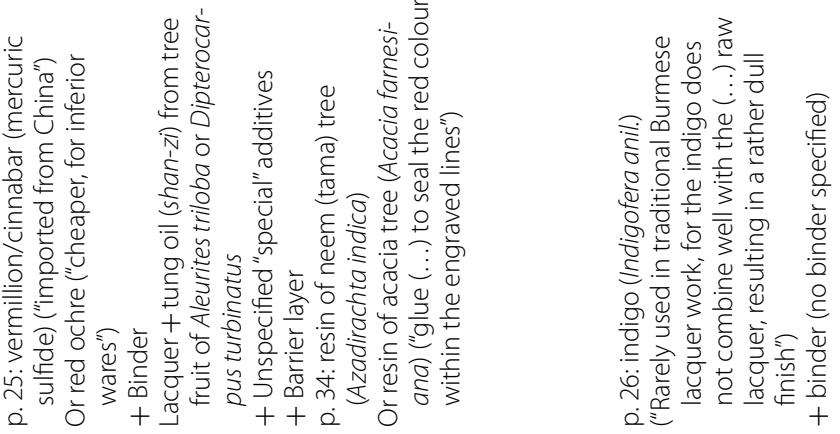

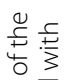

竞

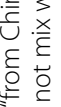
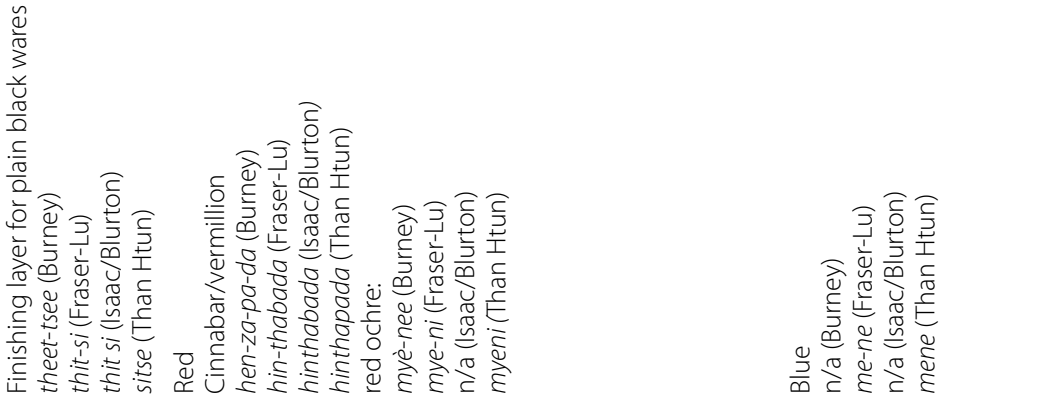


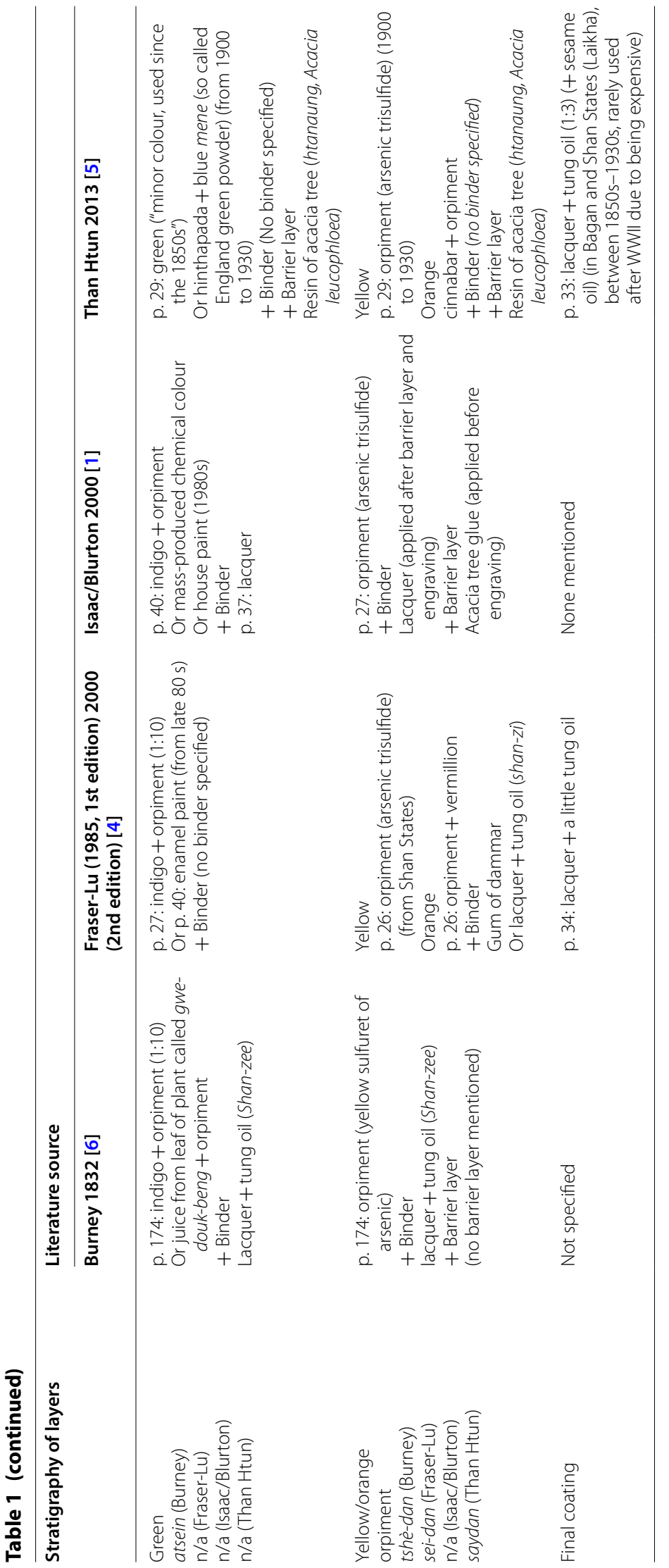


various materials other than lacquer in Burmese objects, but attention to these has always been low [7-9]. Furthermore, pigments play an important role in the final appearance of these objects. Pigments have been studied in a few cases $[7,10]$, but mostly in relation to Japanese and Vietnamese lacquers [11-13]. This work therefore aims to focus attention on identifying materials other than lacquer used for the production of Burmese lacquered objects by applying a systematic multi-analytical approach. In addition to providing scientific evidence for comparison with written sources, this research aims to characterise systems of multiple components, where organic and inorganic materials potentially interact with each other, thus evolving over time in unexpected ways $[14,15]$. Having this information is of paramount importance for the preservation and conservation of these objects. Additionally, the selection of objects was made in order to represent the $y u n$ technique chronologically and geographically over two centuries and to see if there is consistency within the materials used.

From a scientific point of view, lacquered objects are very complex systems and represent an analytical challenge. The main component of the Burmese lacquer sap is a mixture of substituted catechols, referred to as thitsiol [16]. In addition to C15- and C17-alk(en)yl-substituted catechols, which are present in the other Asian lacquers (urushiol and laccol respectively), thitsiol contains catechol derivatives with an $\omega$-phenylalkyl chain of 10 or 12 carbon atoms. These compounds are specific markers of identification of this lacquer [17-20]. When the sap of the tree hardens, a polymerisation process occurs catalysed by the enzyme laccase. The polymeric nature of lacquers makes pyrolysis coupled with gas chromatography and mass spectrometry (Py-GC-MS) the most suitable analytical approach for their chemical analysis, characterisation and identification in samples of unknown composition [12, 21-27]. The need of a derivatisation step, using either tetramethylammonium hydroxide (TMAH) [28-31] or hexamethyldisilazane (HMDS) [8, 14, 20, 32], is strongly suggested due to the large number of polar phenolic compounds produced in the pyrolysis process. The identification is based on the detection of specific molecular markers, as mentioned above, and characteristic profiles of specific classes of pyrolysis products, such as alkylphenols, alkylcatechols, alkylbenzenes and aliphatic hydrocarbons [20,32].

Py-GC-MS can be generally used to identify most classes of organic materials by detecting their molecular markers even in complex mixtures [33]. However, it is sometimes difficult to distinguish between chemically similar substances, such as two vegetable gums or two different oils, because they can easily produce the same pyrolysis products [34]. Comparing chromatographic peak areas sometimes helps to have an approximate distinction, but the values obtained this way are not reliably comparable with data found in the literature and are mainly valid within the laboratory in which they have been obtained. Moreover, Py-GC-MS is not a quantitative technique by definition, as calibration curves for all the compounds found in a pyrogram are virtually impossible to obtain, and, even if done, there is no control over the pyrolysis yield and over the possible interactions between materials affecting the pyrolytic process. For these reasons, analytical procedures based on GC-MS are more reliable when quantitative data are required [35]. Isolation steps and calibration curves enable the chromatographic areas to be directly related to concentrations. Ratios and percentages can therefore be used in a more reliable way for the identification of the sources of certain materials, such as oils, proteins and vegetable gums [36]. In the last decade, analytical methods based on MALDI-ToF and LC-MS have also shown their potential in identifying the exact source of a protein (proteomics) [37] or lipid (lipidomics) [38], but these analyses are still time-consuming and costly compared to GC-MS.

With regards to pigments, Raman spectroscopy is a powerful identification tool $[39,40]$ and can be used noninvasively on the objects themselves. However, lacquered objects usually present a high proportion of organic materials compared to the amount of inorganic pigments, which results in high background fluorescence when using portable instruments directly on the objects [11]. The use of samples, sometimes prepared as cross sections, and an appropriate evaluation of the laser energy to balance the signal intensity and the risk of damaging the samples are highly recommended [11, 12]. The use of cross sections also allows the production of high quality microscopy images of pigment particles, which are fundamental to correctly interpret the results and study the distribution of materials. However, samples for cross sections are relatively large, cannot be further analysed by destructive techniques and double-sampling is therefore required. For ethical reasons, this is sometimes to be avoided for very precious museum objects. Finally, fibre optic reflectance spectroscopy (FORS) is a non-invasive technique, which has recently shown high potential for the straightforward identification of pigments and dyes [41], but has not been applied to lacquerware. The influence of the binding media on the reflectance spectra of the pigments is generally not reported as a major problem, thus making this technique a valid alternative to Raman spectroscopy for the investigation of such objects.

This scientific work represents the first systematic application of this set of complementary techniques (digital microscopy, FORS, Raman, GC-MS and 
Py(HMDS)-GC-MS) to the investigation of the decorative materials of Burmese lacquered objects produced with the $y u n$ technique.

\section{Experimental section}

\section{Selected objects and samples}

Six objects from the British Museum's collection of Burmese lacquerware were selected based on chronological significance and place of production. The objects are all produced using the yun (incised) technique. Object 1 is actually a series of nine plates (registration numbers OA2000,0330.4-12, diameter $26 \mathrm{~cm}$ ) that were made in the late twentieth century to illustrate the technique itself, as it is practised today in Bagan, the most important lacquer-producing centre in Myanmar. These plates show the nine stages necessary to produce this type of object, therefore representing a deconstructed cross section and providing a unique opportunity to investigate the materials utilised in each of the layers. The first plate represents the coiled split bamboo armature covered with a rough layer of lacquer (thayo) (Fig. 1a). Another layer of refined lacquer is then applied (Fig. 1b) and, at this point, the plate is ready for engraving. Once engraved, the red colour is applied (Fig. 1c), followed by further engravings and applications of colour (green and then yellow, Fig. 1d, e). When the decoration is complete, the overall surface is polished (Fig. 1f). Six of these plates (objects $1 \mathrm{a}-\mathrm{f})$ were sampled, representing the different materials, i.e. raw lacquer, refined lacquer, red paint, green paint, yellow paint and final coating. Details of the plates and sampling areas are shown in Fig. 1, and full images of the plates are present in Additional file 1: Figure S1.

Object 2 (registration number OA1996,0501.50, Additional file 1: Figure S2) is a rectangular wooden tray (length $56 \mathrm{~cm}$; width $37 \mathrm{~cm}$ ), showing yellow, red, orange/ pink and green colours on a black ground. All colours were sampled. The object was produced in the 1920s by the artist Ba Htet in the workshop of Ko Aye Hpay in Bagan. Object 3 (registration number OA1998,0723.140, Additional file 1: Figure S3) is approximately contemporary to object 2. It is a Gaduganan betel box (height $15 \mathrm{~cm}$; diameter $19.2 \mathrm{~cm}$ ). The colours are black and red, which were both sampled. Unlike object 2, this object was acquired in the Shan States.

Object 4 (registration number OA1998,0723.206, Additional file 1: Figure S4) is dated to the mid-late nineteenth century from Bagan. It is a water bowl (height $18.8 \mathrm{~cm}$; diameter $23.8 \mathrm{~cm}$ ) showing exquisite decoration in green, yellow and red colours on a black ground, all of which were sampled. Object 5 (registration number OA1996,0501.52, Additional file 1: Figure S5) was a coffer (height $16.5 \mathrm{~cm}$; width $22 \mathrm{~cm}$; length $39 \mathrm{~cm}$ ) dated to the late eighteenth century-early nineteenth century also from Bagan and also showing the three main colours, which were all sampled. Object 6 (registration number OA1998,0723.24, Additional file 1: Figure S6) is a box (height $24 \mathrm{~cm}$; diameter $37 \mathrm{~cm}$ ), possibly for clothes, decorated in black on red ground. The interior surface was painted orange. The black, red and orange colours were all sampled. It is the oldest example of Burmese lacquerware in the BM collection (eighteenth century). The exact place of production is not known.

Additional details about all the objects are present in [1] and Table 2 presents a list of them together with the samples taken and a summary of the results.

\section{Analytical approach}

The selected objects underwent a visual examination to identify the exact number of colours applied and possible sampling locations, mostly at the edge of already damaged areas. The non-invasive analysis by FORS was then conducted followed by a sampling campaign (microsamples of $c$. 50-100 $\mu \mathrm{g}$ were removed from the surface using a micro-scalpel). Black areas were sampled once, as these samples were only analysed by Py(HMDS)GC-MS. Coloured areas were sampled twice: one set of samples underwent GC-MS analysis, whereas the other set was earmarked for microscopic investigation using digital microscopy, Raman analysis and finally Py(HMDS)-GC-MS.

\section{Fibre optic reflectance spectroscopy (FORS)}

Fibre optic reflectance spectra were recorded using an Avantes (Apeldoorn, The Netherlands) AvaSpecULS2048XL-USB2 spectrophotometer equipped with an AvaLight-HAL-S-IND tungsten halogen light source. The detector and light source were connected with a fibre optic bundle to an FCR-7UV200-2-1.5 $\times 100$ probe. The spectral range considered was between 300 and $900 \mathrm{~nm}$. As per the features of the monochromator (slit width $50 \mu \mathrm{m}$, grating of UA type with 300 lines $/ \mathrm{mm}$ ) and of the detector (2048 pixels), the best spectra resolution was $2.4 \mathrm{~nm}$. Spectra were referenced against the WS-2 reference tile provided by Avantes. The diameter of the investigated area on the sample was approximately $1 \mathrm{~mm}$. The instrumental parameters were as follows: $50 \mathrm{~ms}$ integration time, 20 scans for a total acquisition time of $1 \mathrm{~s}$ for each spectrum. The whole system was managed by the software AvaSoft 8 for Windows ${ }^{\mathrm{TM}}$. Spectra were acquired in reflectance mode $(\mathrm{R})$ and then transformed into apparent absorption spectra by plotting the $\log (1 / \mathrm{R})$.

\section{Digital microscopy (DM)}

A Keyence VHX-5000 digital microscope was used to record the magnified images $(500-2000 \times)$ of the samples. The Keyence microscope was used with a lens VH-Z 

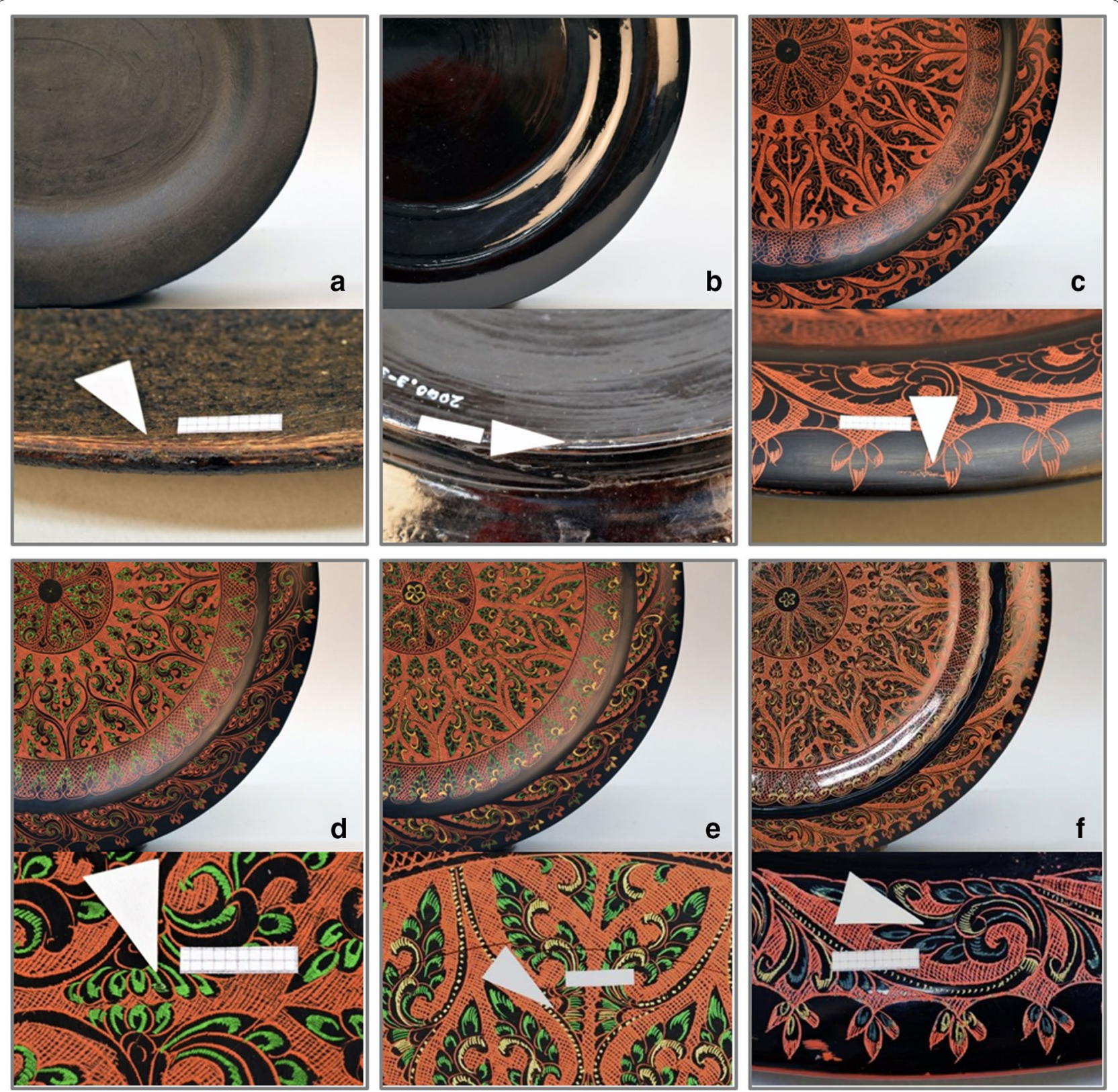

Fig. 1 Details of the series of plates (objects 1a-f) illustrating the yun process: a application of raw lacquer (the plate is from the same workshop but not from the same production group as the others); $\mathbf{b}$ application of refined lacquer; $\mathbf{c}$ engraving and application of red paint; $\mathbf{d}$ application of green paint; e application of yellow paint; $\boldsymbol{f}$ finished product. The diameter of the plates is $26 \mathrm{~cm}$. Sampling areas are shown for each plate (scale bar $1 \mathrm{~cm})$

Z250R/W, an automated stage VHX-S 550E and LED reflected illumination.

\section{Raman spectroscopy}

A Jobin-Yvon LabRam Infinity spectrometer was used with a green laser $(532 \mathrm{~nm})$ with maximum power of 2.4 $\mathrm{mW}$ at the sample, a liquid nitrogen cooled CCD detector and an Olympus microscope system. The instrument was calibrated using a silicon standard, with a wavenumber deviation of $3 \mathrm{~cm}^{-1}$. The experimental conditions were: integration time between 5 and $10 \mathrm{~s}$, averaging of up to 50 scans, spectral range between 135 and $2600 \mathrm{~cm}^{-1}$ and a fine grating of $1800 \mathrm{~g} / \mathrm{mm}$. The analyses were carried out on the samples, trying to target differently coloured particles. 


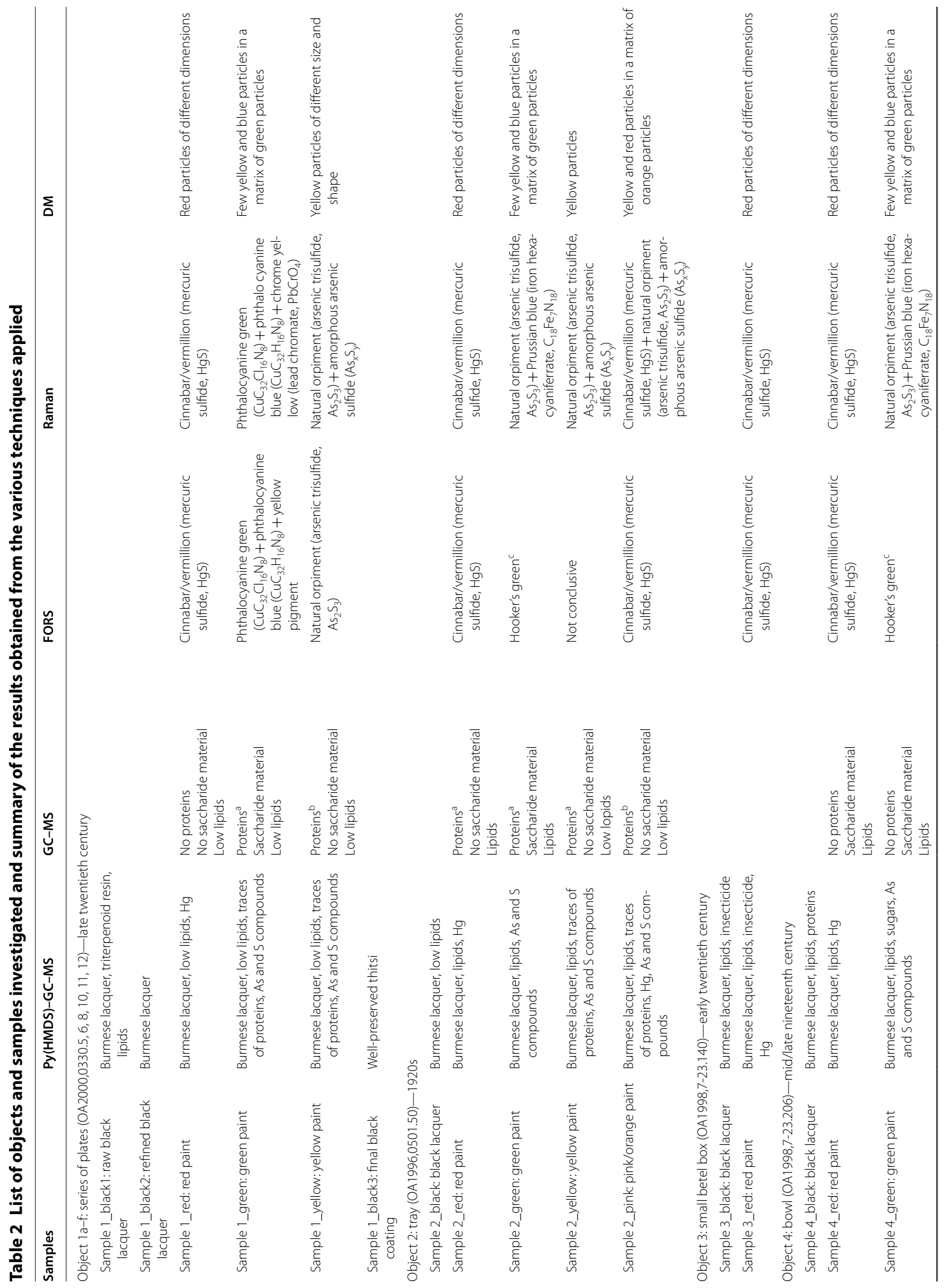




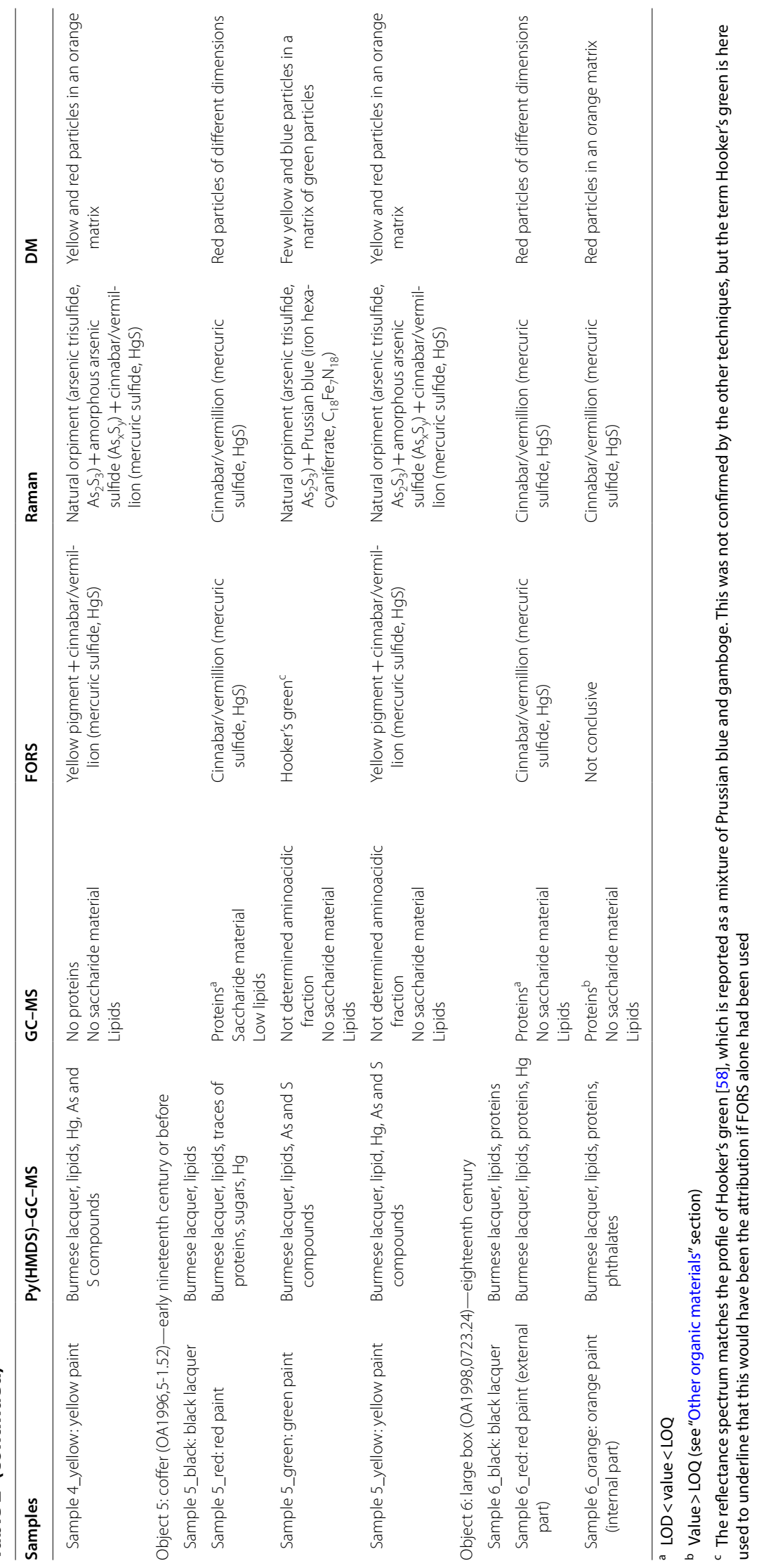




\section{Py(HMDS)-GC-MS}

Analytical pyrolysis was performed using 1,1,1,3,3,3-hexamethyldisilazane (HMDS, chemical purity 99.9\%, Sigma Aldrich Inc., USA) as a silylation agent for the in situ thermally-assisted derivatisation of pyrolysis products. The instrumentation consisted of a 1500 CDS Pyroprobe 1000 Series filament pyrolyser (CDS Analytical, USA) (platinum coil) coupled to a gas chromatograph 6890 (Agilent Technologies, USA) equipped with an HP5MS fused silica capillary column $(30 \mathrm{~m} \times 0.25 \mathrm{~mm}$ i.d., $0.25 \mu \mathrm{m}$ thickness, Agilent Technologies, USA). The GC was coupled with an Agilent 5973 Mass Selective Detector operating in electron impact mode (EI) at $70 \mathrm{eV}$. Pyrolysis temperature was $550^{\circ} \mathrm{C}$ and the interface temperature was $275{ }^{\circ} \mathrm{C}$. Similar amounts $(c .50-100 \mu \mathrm{g})$ of sample and HMDS $(2 \mu \mathrm{L})$ were inserted into the centre of the pyrolysis quartz tube with quartz wool and then put into the filament coil. The GC injector was used with a split ratio of $1: 10$ at $300{ }^{\circ} \mathrm{C}$. Chromatographic conditions were as follows: initial temperature $36{ }^{\circ} \mathrm{C}, 10 \mathrm{~min}$ isothermal, $10{ }^{\circ} \mathrm{C} \mathrm{min}-1$ up to $280{ }^{\circ} \mathrm{C}, 2 \mathrm{~min}$ isothermal; $20{ }^{\circ} \mathrm{C} \mathrm{min}{ }^{-1}$ up to $310{ }^{\circ} \mathrm{C}, 20 \mathrm{~min}$ isothermal. Helium (purity 99.995\%) was used as carrier gas with a constant flow of $1.0 \mathrm{~mL} \mathrm{~min}{ }^{-1}$.

\section{GC-MS}

A microwave MLS-1200 MEGA (Milestone Microwave Laboratory System), High Performance Microwave Digestion with Exhaust Module EM-45/A was used for the hydrolysis and the saponification of the sample fractions prior to GC-MS analysis [42].

The GC-MS system was the same described in the previous section, apart from the injector, which was a PTV injector (Agilent Technologies).

A combined procedure that allows the separation and characterisation in the same micro-sample of three different fractions corresponding to saccharide, proteinaceous and lipid-resinous materials was used for the GC-MS analysis. The analytical procedure was based on the ammonia extraction of proteins and polysaccharide materials from the sample in order to separate them from lipid and resinous materials. Proteinaceous and saccharide fractions were separated by a monolithic sorbent tip featuring a $\mathrm{C} 4$ stationary phase and were subsequently hydrolysed and purified. Lipids and resins were subjected to saponification. The detailed operating conditions and analytical procedure are described elsewhere [42].

Proteinaceous materials were identified based on the percentage composition of 11 determined amino acids, which were subjected to principal component analysis (PCA), together with a data-set of 121 reference samples of animal glue, egg and casein [43, 44]. The first two principal components accounted for $96.3 \%$ of the data.
The presence and absence of specific sugars (aldoses and uronic acids) were used for the identification of the saccharide content by decisional schemes described in the literature $[45,46]$.

The quantitative determination of amino acids, aldoses and uronic acids, aliphatic mono- and dicarboxylic acids was performed by using standard solutions, building calibration curves, and evaluating daily recoveries. Running blanks of the procedure highlighted a low level of contamination. The detection limit (LOD) and the quantitation limit (LOQ) of amino acids, aldoses, uronic acids, and fatty and dicarboxylic acids were calculated. At a statistical significance level of 0.05, the LODs and LOQs obtained for the proteinaceous material were $0.19 \mu \mathrm{g}$ and $0.30 \mu \mathrm{g}$ respectively; for the glycerolipids $0.35 \mu \mathrm{g}$ and $0.50 \mu \mathrm{g}$ respectively; and for the saccharide material $0.01 \mu \mathrm{g}$ and $0.02 \mu \mathrm{g}$ respectively.

\section{Results \\ Pigments \\ Red}

The red colour was present in all the objects under investigation. The reflectance spectra acquired by FORS of all the red areas produced the same steep sigmoid-shaped spectrum with an inflection point at ca. $590 \mathrm{~nm}$, which is typical of cinnabar/vermillion (mercuric sulfide, $\mathrm{HgS})^{2}$ (Fig. 2). The literature reports the inflection point to be more towards $600 \mathrm{~nm}[41,47]$, but a contribution due to the lacquer medium might be the reason for this slight shift. The apparent absorption spectra showed a reversed sigmoid-shaped spectrum with an inflection point at ca. $580 \mathrm{~nm}$ (Fig. 2).

Samples (1_red, 2_red, 3_red, 4_red, 5_red and 6_red) were taken from all the red areas and underwent digital microscopy examination. Generally, it was not always possible to completely eliminate the shiny effect produced by the high reflective properties of the lacquer itself, but this did not affect the interpretation of the images in most cases. The samples showed a very fine (low- $\mu \mathrm{m}$ scale) and relatively homogeneous distribution of red particles (Fig. 3a), but irregular edges and bigger particles were generally present. This pointed towards the use of natural cinnabar or vermillion obtained through a dry process rather than a wet process [48].

The Raman spectra acquired on the micro-samples confirmed $\mathrm{HgS}$ to be the red pigment (Fig. 4a). The main absorption band at ca. $255 \mathrm{~cm}^{-1}$ was clearly visible in all

\footnotetext{
${ }^{2}$ Cinnabar refers to the natural mineral form of $\mathrm{HgS}$ and vermillion refers to the synthetic form, which can be produced by wet or dry processes. The vis$\mathrm{ual} /$ microscopical distinction of the different forms is sometimes possible but usually not straightforward, therefore the terms are often used interchangeably.
} 

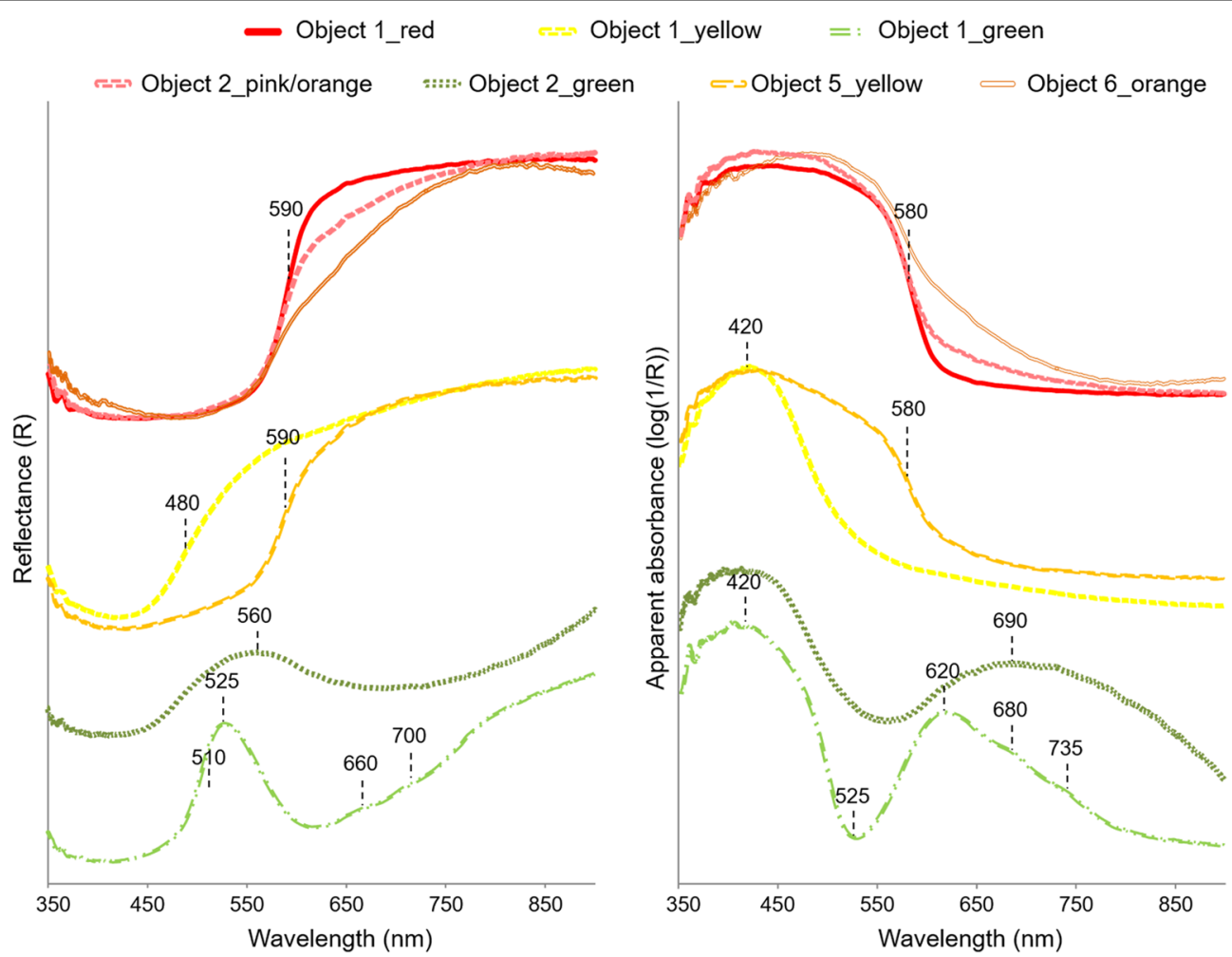

Fig. 2 Reflectance (left) and apparent absorption (right) spectra obtained by FORS for representative areas of object 1 (red =cinnabar/vermillion; yellow $=$ orpiment; green $=$ phtalo green + phthalo blue + chrome yellow), object 2 (pink/orange $=$ cinnabar/vermillion; green $=$ Prussian blue + orpiment), object 5 (yellow $=$ cinnabar/vermillion + orpiment) and object 6 (orange $=$ unidentified)

spectra, but the detection of the two minor bands at ca. 285 and $345 \mathrm{~cm}^{-1}$, which complete the signature fingerprint of cinnabar/vermillion [11], was dependent on the quality of the analysed spot.

The extraction of the ion with $m / z$ (mass/charge ratio) 202 (Additional file 1: Figure S7a) from the chromatograms obtained by Py(HMDS)-GC-MS of all red samples revealed the presence of a broad peak, which can be assigned to molecular mercury $(\mathrm{Hg})$, as confirmed by the isotopic distribution ranging from 196 to $204 \mathrm{~m} / \mathrm{z}$. This is a reduction product of $\mathrm{HgS}$, which can also be used as indication of the presence of cinnabar or vermillion $[27,49]$.

\section{Yellow}

Yellow decoration was present in objects 1, 2, 4 and 5 . The yellow areas in object 1 produced reflectance spectra with a simple sigmoid shape and an inflection point at ca. $480 \mathrm{~nm}$, suggesting the presence of natural orpiment (arsenic trisulfide, $\mathrm{As}_{2} \mathrm{~S}_{3}$ ) (Fig. 2) [41, 47]. None of the other yellow areas from the other objects produced such clear spectra. For object 2, a much flatter spectrum was obtained, whereas for objects 4 and 5 a red contribution was present in the spectra (Fig. 2), with an inflection point at ca. $590 \mathrm{~nm}$, which suggested a mixture of a yellow pigment with cinnabar/vermillion.

These observations were clarified when digital microscopy was applied to the micro-samples taken from these yellow areas. Samples 1_yellow and 2_yellow only contained yellow particles (Fig. 3b), whereas samples 4_yellow and 5_yellow revealed the presence of yellow and red particles (Fig. 3c). Raman spectroscopy enabled single particles to be targeted. The red particles were again identified as $\mathrm{HgS}$. Most of the yellow particles produced the signature spectrum of natural orpiment $\left(\mathrm{As}_{2} \mathrm{~S}_{3}\right)$, as indicated by the absorption bands at ca. 155, 180, 205, 294, 312, 356 and $385 \mathrm{~cm}^{-1}$ [50] (Fig. 4b). However, some particles in these samples, especially from samples 1_yellow, 2_yellow and 4_yellow, showed a much less resolved spectrum with a broad band centred at ca. $343 \mathrm{~cm}^{-1}$ (Fig. 4c). This was consistent with the presence of amorphous arsenic sulfide [50]. The spectra for these particles also showed minor bands at ca. 233 and $495 \mathrm{~cm}^{-1}$, which are attributed to realgar-like nano phase and are considered to be indicative of a heat process used to produce the amorphous pigment [51]. This hypothesis was also supported by the fact that some other particles in these 

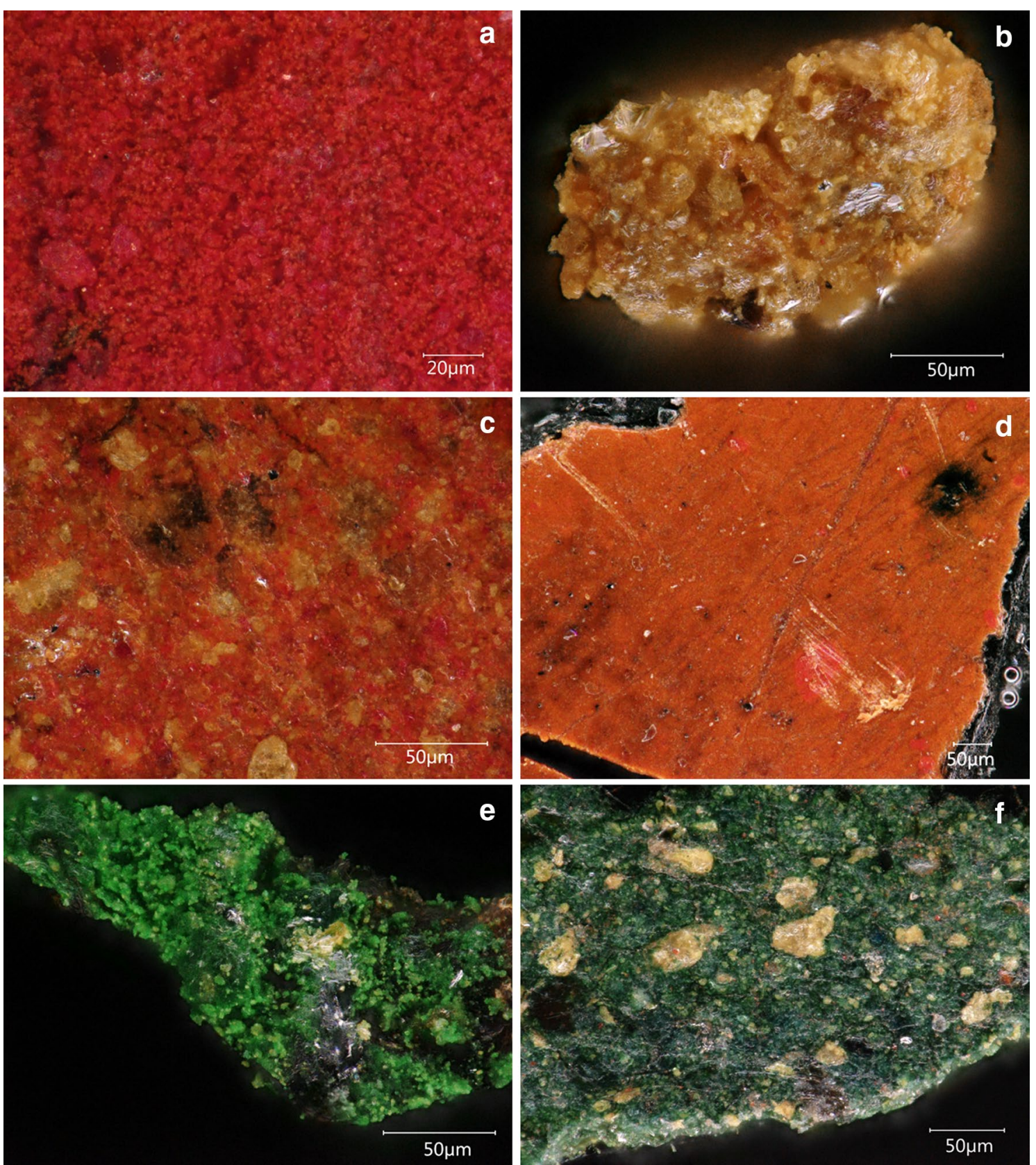

Fig. 3 Images obtained by digital microscopy of samples a 4_red, b 2_yellow, c 5_yellow, d 6_orange, e 1_green and $\mathbf{f}$ 5_green, representative of the appearance of most samples

samples showed mixed features between natural orpiment and amorphous arsenic sulfide. These observations can be taken as indication of the production of amorphous arsenic sulfide by sublimation of natural orpiment $[50,51]$.

Also in the case of the yellow samples, Py(HMDS)GC-MS provided an indication for the presence of arsenic sulfide pigments. In fact, peaks attributed to $\mathrm{As}_{4}$
( $m / z$ 299.6), $\mathrm{As}_{4} \mathrm{~S}_{3}(395.6 \mathrm{~m} / z), \mathrm{As}_{4} \mathrm{~S}_{4}(m / z$ 427.6), arsenous acid $\left(\mathrm{H}_{3} \mathrm{AsO}_{3} ; \mathrm{MW}=342 \mathrm{u}\right)$, arsenic acid $\left(\mathrm{H}_{3} \mathrm{AsO}_{4}\right.$; $\mathrm{MW}=358 \mathrm{u})$ and arsenolite $\left(\mathrm{As}_{4} \mathrm{O}_{6}\right)$ were generally detected in the yellow samples and could be extracted by using the ion with $m / z 207$ (Additional file 1: Figure S7b). Some of these compounds have already been reported as indicators of the presence of arsenic sulfide pigments using Py-GC-MS [13, 52]. 


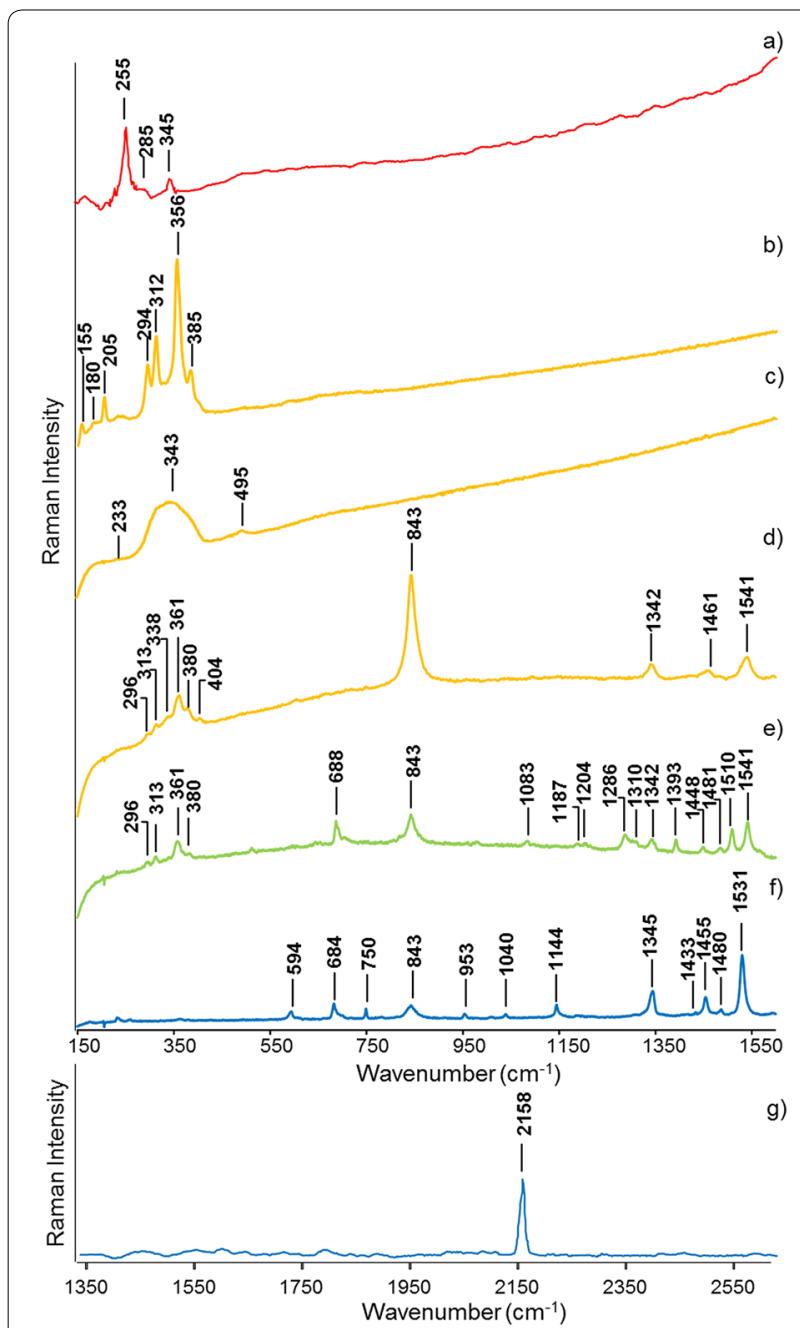

Fig. 4 Raman spectra obtained for samples a 4_red (red particlecinnabar/vermillion), b 2_yellow (yellow particle-orpiment), c 2_yellow (different yellow particle-amorphous arsenic sulfide), d 1 _ green (yellow particle — chrome yellow and phthalocyanine green), e 1_green (green particle-phthalocyanine green and chrome yellow), $\mathbf{f}$ 1_green (blue particle_-phthalocyanine blue) and $\mathbf{g}$ 5_green (blue particle-Prussian blue)

\section{Pink/orange}

Object 2 has areas with a pink/orange colouration. The reflectance spectra (Fig. 2) highlighted the presence of cinnabar/vermillion, as observed for the red areas. However, the digital microscope images of the corresponding sample 2_pink clearly showed the presence of red and yellow particles (Additional file 1: Figure S2), which were identified by Raman as cinnabar/vermillion and a mixture of natural orpiment and amorphous arsenic sulfide.

The internal part of object 6 showed an orange colouration. FORS spectra were not conclusive for the identification of the pigment (Fig. 2). Digital microscopy of sample 6_orange revealed a few red particles (identified as cinnabar/vermillion by Raman) (Fig. 3d) embedded in a homogeneous orange matrix, which only produced intense fluorescence in the Raman spectra. Further discussion about this sample is presented in "Discussion" section.

\section{Green}

Green decoration was present in objects 1, 2, 4 and 5 . The reflectance spectra from the green areas of object 1 showed a relatively sharp band with maximum at ca. $525 \mathrm{~nm}$ and at least two minor bands at ca. 660 and $700 \mathrm{~nm}$ (Fig. 2), which are reported to be characteristic of phthalocyanine blue $\left(\mathrm{CuC}_{32} \mathrm{H}_{16} \mathrm{~N}_{8}\right)$ and phthalocyanine green $\left(\mathrm{CuC}_{32} \mathrm{Cl}_{16} \mathrm{~N}_{8}\right)$, respectively, therefore pointing towards a possible mixture of these two synthetic pigments [53]. The sharp maximum, which is common to both pigments, is generally reported to be centred at lower wavelengths (490-500 nm) $[47,53]$, but mixtures with yellow pigments can result in a shift towards the observed wavelength [53]. The apparent absorption spectra confirmed these observations, showing an absorption feature related to a yellow pigment (ca. $420 \mathrm{~nm}$ ), and at least three bands at ca. 620, 680 and $735 \mathrm{~nm}$ (Fig. 2) indicated a mixture of phthalo blue and phthalo green [53].

Observations under the digital microscope of sample 1_green showed a distribution of bright green particles with a few yellow and blue particles visible in some areas (Fig. 3e). When the yellow particles were targeted by Raman spectroscopy, chrome yellow (lead chromate, $\left.\mathrm{PbCrO}_{4}\right)$ was identified thanks to the typical strong absorption band at $843 \mathrm{~cm}^{-1}$ and the series of absorption bands at ca. 296, 313, 338, 361, 380 and $404 \mathrm{~cm}^{-1}[40,54$, 55] (Fig. 4d). Blue particles were found to be composed of phthalocyanine blue, whose spectrum showed a complex array of absorption bands (1531, 1480, 1455, 1433, $1345,1144,1040,953,750,684$ and $\left.594 \mathrm{~cm}^{-1}\right)[11,40,56$, 57] (Fig. 4f). Different absorption bands were obtained in the Raman spectra recorded on the green particles (1541, $1510,1481,1448,1393,1342,1310,1286,1204,1187$, 1083 and $688 \mathrm{~cm}^{-1}$ ) (Fig. 4e), which enabled the phthalocyanine green to be identified $[40,57]$.

On the other hand, the reflectance spectra from the green areas of objects 2, 4 and 5 showed a broad band centred at ca. $560 \mathrm{~nm}$ with a dropping off after $580 \mathrm{~nm}$ (Fig. 2). This was consistent with the so-called Hooker's green pigment, originally produced as a mixture of Prussian blue (iron hexacyanoferrate, $\mathrm{C}_{18} \mathrm{Fe}_{7} \mathrm{~N}_{18}$ ) and gamboge (yellow gum resin produced from various trees growing in south Asia) [58]. The digital microscopy images of samples 2_green, 4_green and 5_green showed large yellow particles in a matrix of blue and green particles (Fig. 3f). The yellow particles targeted by Raman were all identified as natural orpiment and/or amorphous 
arsenic sulfide. The Raman spectra obtained from the blue particles enabled the identification of Prussian blue, mainly from its characteristic absorption band at ca. $2158 \mathrm{~cm}^{-1}$ [11] (Fig. 4g). The spectra from the green areas also showed the presence of Prussian blue and an intense background fluorescence. Peaks ascribable to gamboge were not detected by Raman. Fourier transform infrared (FTIR) spectroscopy in transmission mode and high pressure liquid chromatography mass spectrometry (HPLC-MS) after extraction were also applied to these samples with the aim to highlight the presence of gamboge, but this resin was not detected. It is likely that the particular combination of thitsi, orpiment and Prussian blue resulted in a FORS spectrum similar to Hooker's green, but the green colour appeared to be created as a mixture of arsenic sulfide pigments and Prussian blue.

Py(HMDS)-GC-MS of sample 1_green showed the unusual presence and high relative abundance of some aromatic compounds, such as styrene, indene and naphthalene, which may indicate the presence of phthalo blue and phthalo green pigments [59]. Nevertheless, chlorinated compounds, which are usually reported as pyrolysis products of green phthalocyanines [59], were not detected in the adopted conditions. The pyrograms of samples $2 \mathrm{c}, 4 \mathrm{c}$ and $5 \mathrm{c}$ showed the presence of the As and $\mathrm{S}$ pyrolysis products, as observed for the yellow samples.

\section{Burmese lacquer}

All samples contained Burmese lacquer (thitsi), confirming the use of the Melanorrhoea (Gluta) usitata tree as the source of the lacquer, and therefore the results of the analyses were in agreement with the geographical origin of these objects. The identification was achieved by Py(HMDS)-GC-MS (Figs. 5a and 6a), which enabled the detection of the thitsi markers $\omega$-phenylalkyl catechols $(\omega-\mathrm{CT})$ and phenols $(\omega-\mathrm{Ph})$ in their trimethylsilyl (TMS) forms. Furthermore, pyrolytic profiles of the mono-TMS alkylcatechols (CT) and alkylphenols (Ph) were extracted using the ions with $\mathrm{m} / z 179$ and 180 respectively (Fig. 5b) [20]. These profiles highlighted the presence of other catechols and phenols, in particular 3-pentadecylcatechol (CT-15) and 3-pentadecylphenol (Ph-15), which are naturally present in the lacquer sap [18], but also other short-chain alkylcatechols and alkylphenols, which derive from the pyrolytic cleavage of the alkyl chains. When comparing the profiles of all analysed samples with each other, the molecular markers for thitsi were shown in high relative abundance in all samples from object 1 (late twentieth century), but they showed a progressive reduction in their relative abundance from object 2 to object 6 (early twentieth century to eighteenth century). On the other hand, for objects 4, 5, and 6-the oldest amongst the sampled objects-CT-15 and Ph-15 were predominant in the corresponding pyrolytic profiles with comparison to $\omega-\mathrm{CT}$ and $\omega-\mathrm{Ph}$. This observation is important, as these two molecules (CT-15 and Ph-15) are considered the molecular markers for urushi (Rhus vernicifera) [32] and the distinction between the two lacquers or their mixture in old objects can become difficult if interpretation is only based on the profile/presence of alkylcatechols and alkylphenols.

The pyrolytic profiles of other compounds were therefore investigated to characterise possible lacquer mixtures or distinguish aged thitsi from urushi. Helpfully, the pyrolysis of thitsi produces a characteristic Gaussian-like profile of alkylbenzenes (B), which was extracted using the ion with $m / z 91$ (Fig. 5c). Undecenylbenzene (B11:1) is usually the most abundant pyrolysis product, derived from the cleavage at the benzylic position of 3 -and 4-(12-phenyldodecyl)catechols in the polymeric network [20], although in some cases dodecylbenzene (B12) has a higher relative abundance. All the samples showed this characteristic pyrolytic profile, which allowed us to rule out urushi being mixed with thitsi for objects 4, 5 and 6 , as urushi produces a very different profile of alkylbenzenes [32]. Aliphatic hydrocarbons (C), whose pyrolytic profile was extracted using the ion with $\mathrm{m} / z 57$ (Fig. 5d), also represent an important category of pyrolysis products, but they are generally not helpful in distinguishing between thitsi and urushi, as tetradecene (C14:1) and pentadecane $(\mathrm{C} 15)$ are the most abundant aliphatic hydrocarbons produced in the pyrolysis of both types of lacquer [20, 32].

For aged Burmese lacquer other classes of pyrolysis products are also reported, such as alkylphenylketones (K), alkylphenylcarboxylic acids (Ph-A) and alkyl-oxophenylcarboxylic acids (Ox-A) [8] (Fig. 6). The formation of the alkylphenylketones is attributed to the oxidation of the benzylic position of the alkylphenylcatechols and phenols, whereas an oxidative cleavage of the catechol ring has been proposed to explain the formation of alkylphenylcarboxylic acids and alkyl-oxo-phenylcarboxylic acids [8]. For the objects under investigation, these oxidation products were almost absent in all the samples from object 1 , but their relative abundance progressively increased in objects 2 to 6 .

This trend was opposite to the observed decrease in relative abundance of alkylphenylcatechols and phenols, hinting at their degradation with increasing age. In order to visualise these trends, chromatographic areas of specific pyrolysis products were integrated and ratios were calculated for all the lacquer samples (Fig. 7). Regarding alkylphenylcatechols and phenols, the chromatographic areas of all the $\omega$-(10-phenyldecyl)catechols and phenols and $\omega$-(12-phenyldodecyl)catechols and phenols isomers were summed, as well as the areas of 3-pentadecylphenol 


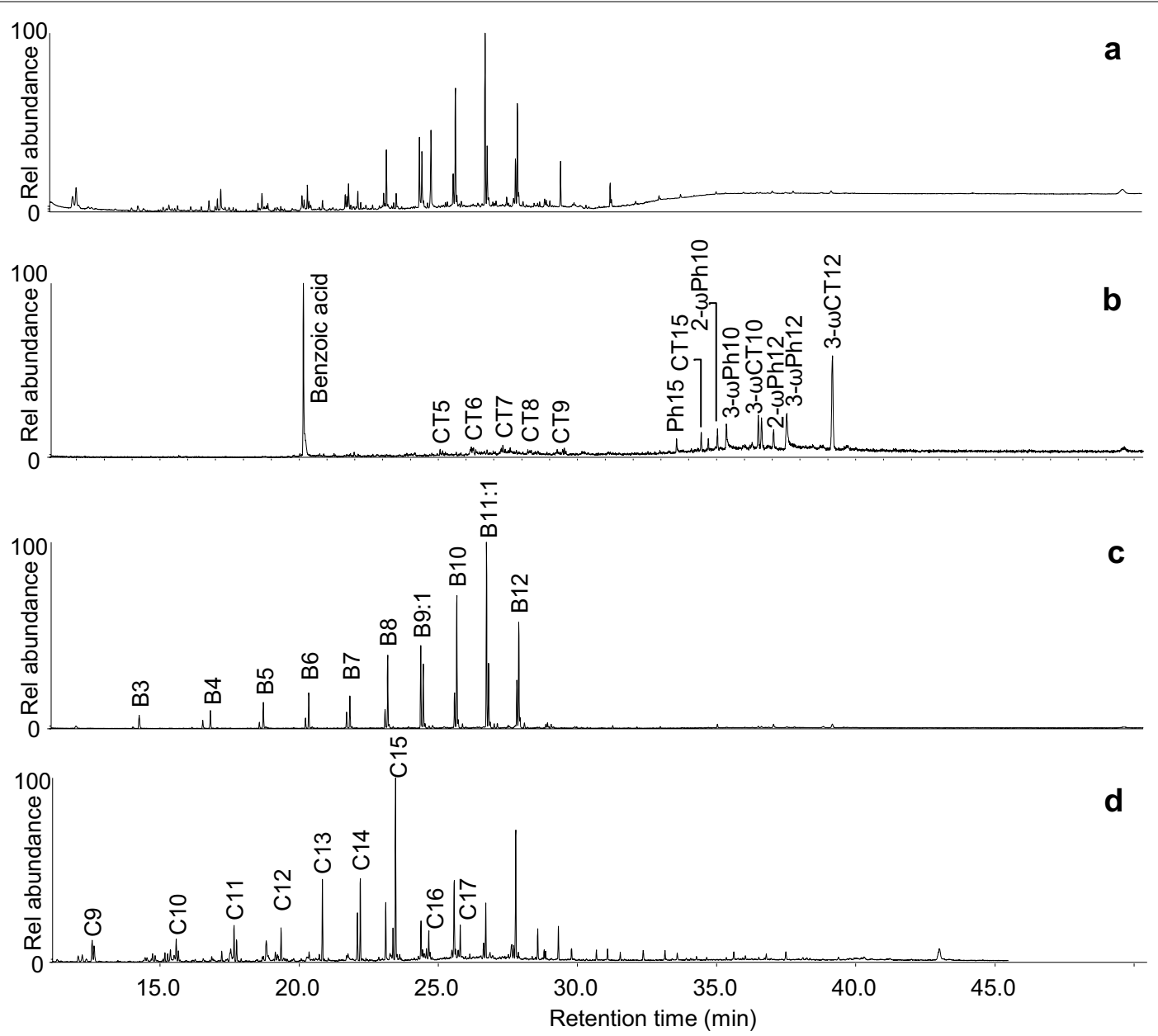

Fig. 5 Chromatographic profiles obtained by Py(HMDS)-GC-MS of sample 1_black2 (late twentieth century. a Total ion chromatogram; b extracted ion chromatogram of the ion with $\mathrm{m} / \mathrm{z}$ 179, showing CT5) 3-pentylcatechol (TMS), CT6) 3-hexylcatechol (TMS), CT7) 3-heptylcatechol (TMS), CT8) 3-octylcatechol (TMS), CT9) 3-nonylcatechol (TMS), Ph15) 3-pentadecylphenol (TMS), CT15) 3-pentadecylcatechol (TMS), 2- $\omega$ Ph10)

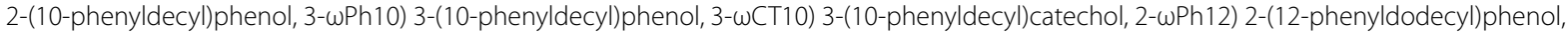

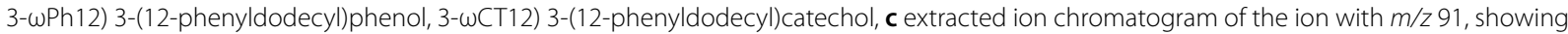
B3) propylbenzene, B4) butylbenzene, B5) pentylbenzene, B6) hexylbenzene, B7) heptylbenzene, B8) octylbenzene, B9:1) nonenylbenzene, B10) decylbenzene, B11:1) undecenylbenzene, B12) dodecylbenzene, $\mathbf{d}$ extracted ion chromatogram of the ion with $\mathrm{m} / \mathrm{z}$ 57, showing (9) nonane, C10) decane, (11) undecane, C12) dodecane, (13) tridecane, C14) tetradecane, C15) pentadecane, C16) hexadecane, C17) heptadecane

and 3-pentadecylcatechol. A ratio between these two values was then calculated, according to the formula

$$
\begin{gathered}
(2-\omega \mathrm{Ph} 10+3-\omega \mathrm{Ph} 10+2-\omega \mathrm{Ph} 12+3-\omega \mathrm{Ph} 12 \\
+3-\omega \mathrm{CT} 10+3-\omega \mathrm{CT} 12) /(\mathrm{Ph} 15+\mathrm{CT} 15) .
\end{gathered}
$$

This ratio was referred to as $\omega \mathrm{CT} / \mathrm{CT}$ ratio.

With regards to the oxidation products, alkylphenylketones (K) and alkylbenzenes (B) were considered and the most abundant peaks in each profile were chosen as representatives. These corresponded to 1-phenylundecen-1-one and undecenylbenzene (K11:1/B11:1) in most cases or 1-phenyldodecan-1-one and dodecylbenzene (K12/B12) in a few cases. This ratio was referred to as the $\mathrm{K} / \mathrm{B}$ ratio. The results of these calculations are shown in Fig. 7.

As mentioned above, the meaning of the $\mathrm{K} / \mathrm{B}$ ratio is straightforward, as this is directly related to the oxidation of the benzylic position in alkylphenylcatechols and phenols. It therefore appears that there is a clear correlation between the oxidation of the lacquer and the age of the object. On the other hand, the $\omega \mathrm{CT} / \mathrm{CT}$ ratio can be considered as an indirect index of the same process. As alkylphenylcatechols and phenols undergo oxidation at the benzylic position, they become more prone 

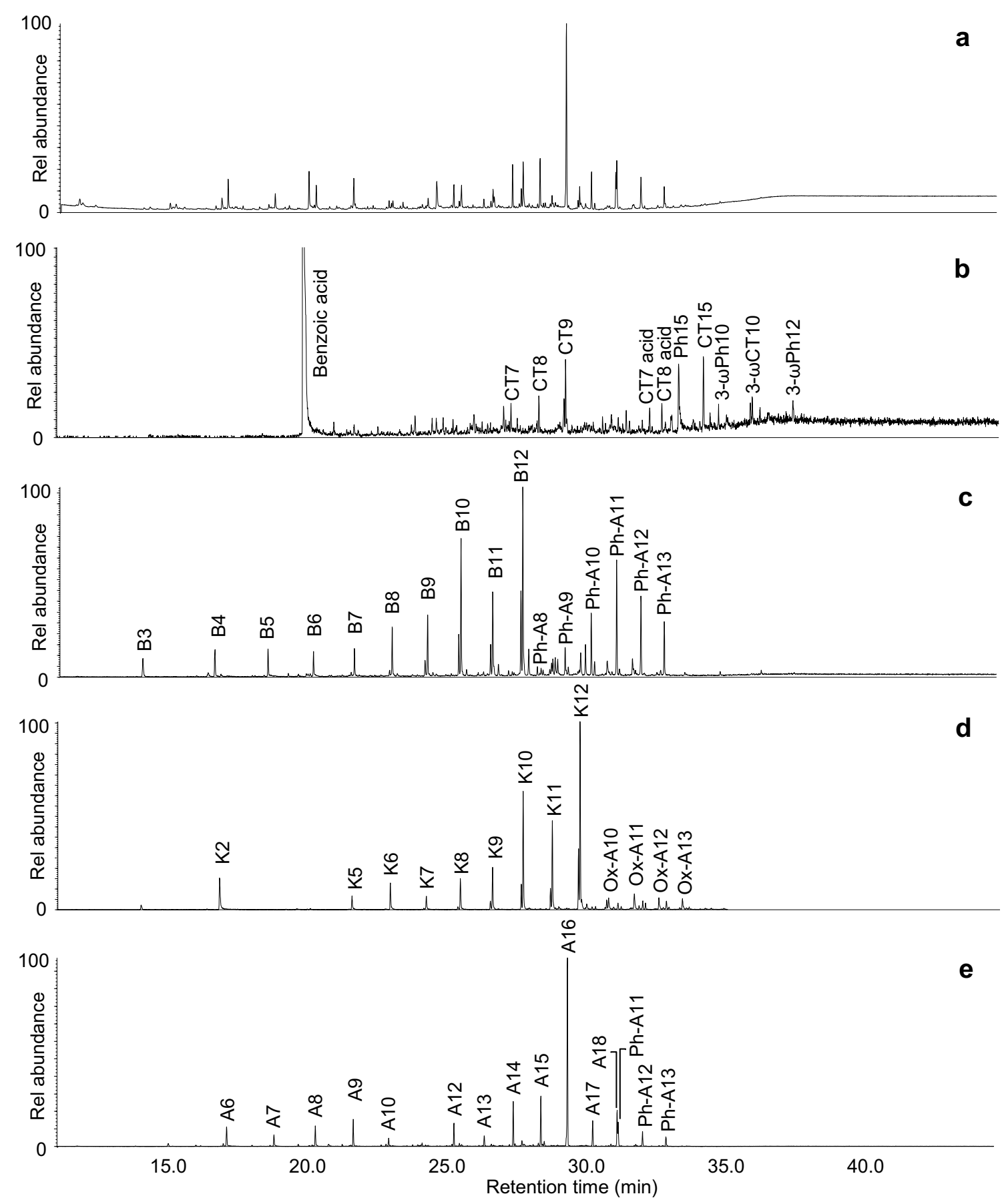

Fig. 6 Chromatographic profiles obtained by Py(HMDS)-GC-MS of sample 5_black (early nineteenth century or before). a Total ion chromatogram; b extracted ion chromatogram of the ion with $\mathrm{m} / \mathrm{z}$ 179, showing CT7-acid) 7-(2,3-dihydroxyphenyl)heptanoic acid (2TMS), CT8-acid) 8-(2,3-dihydroxyphenyl)octanoic acid (2TMS); c extracted ion chromatogram of the ion with $\mathrm{m} / \mathrm{z}$ 91, showing Ph-A8) 8-phenyloctanoic acid, Ph-A0) 9-phenylnonanoic acid (TMS), Ph-A10) 10-phenyldecanoic acid (TMS), Ph-A11) 11-phenylundecanoic acid (TMS), Ph-A12) 12-phenyldodecanoic acid (TMS), Ph-A13) 13-phenyltridecanoic acid (TMS); d extracted ion chromatogram of the ion with $\mathrm{m} / \mathrm{z}$ 120, showing K5) 1-phenylpentan-1-one, K6) 1-phenylhexan-1-one, K7) 1-phenylheptan-1-one, K8) 1-phenyloctan-1-one, K9) 1-phenylnonan-1-one, K10) 1-phenyldecan-1-one, K11) 1-phenylundecan-1-one, K12) 1-phenyldodecan-1-one, Ox-A10) 10-oxo-10-phenyldecanoic acid (TMS), Ox-A11) 11-oxo-11-phenylundecanoic acid (TMS), Ox-A12) 12-oxo-12-phenyldodecanoic acid (TMS), Ox-A13) 13-oxo-13-phenyltridecanoic acid (TMS); e extracted ion chromatogram of the ion with $\mathrm{m} / \mathrm{z}$ 117, showing A5) pentanoic acid (TMS), A6) hexanoic acid (TMS), A7) heptanoic acid (TMS), A8) octanoic acid (TMS), A9) nonanoic acid (TMS), A10) decanoic acid (TMS), A12) dodecanoic acid (TMS), A13) tridecanoic acid (TMS), A14) tetradecanoic acid (TMS), A15) pentadecanoic acid (TMS), A16) hexadecanoic acid (TMS), A17) heptadecanoic acid (TMS), A18) octadecanoic acid (TMS). Unlisted compounds are present in the caption of Fig. 5 


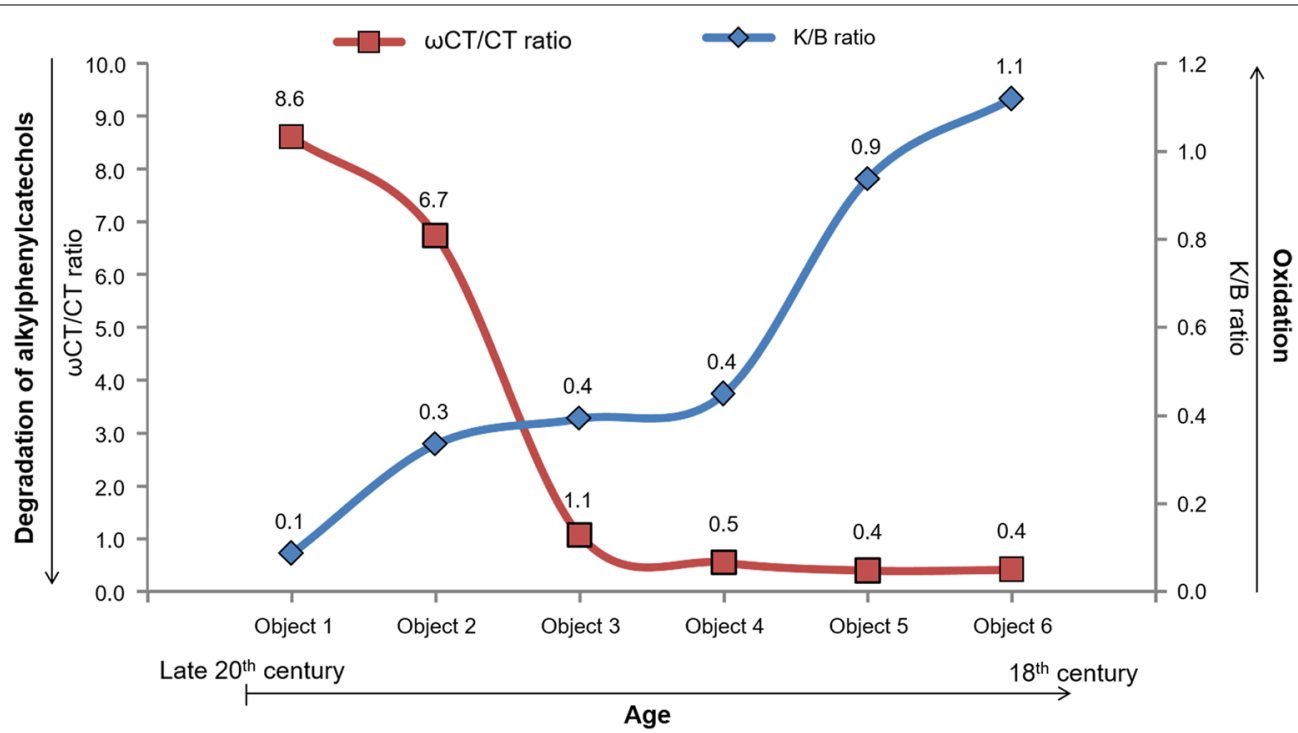

Fig. 7 Graphical representation of the $\omega C T / C T$ and K/B ratios calculated for the lacquer samples of the six objects under investigation

to subsequent degradation and, considering the radical nature of the oxidation, they can evolve in different ways within the polymeric network [8]. Consequently, their relative abundance is reduced. By contrast, alkylcatechols and phenols do not have a benzylic position suitable for such oxidation. They are therefore more stable and the result is an increase in their relative abundance. Also in this case, a direct trend with the age of the object was expected and obtained.

\section{Other organic materials (resins, lipids, proteins and polysaccharides)}

Py(HMDS)-GC-MS analysis of sample 1_black1 (raw lacquer) revealed the presence of a triterpenoid dammarlike resin, as suggested by the detection of 20,24-epoxy25-hydroxy-dammaran-3-one and other dammarane and oleanane derivatives [60].

GC-MS analyses highlighted a very low level of lipid material, which was around the detection limit (LOD) of the analytical procedure, for all the samples from object 1 and for samples 2_yellow and 2_pink. By contrast, the presence of a lipid material was highlighted in all the other samples. The distinction between siccative, semi-siccative and non-siccative oils in this kind of analysis is generally based on the ratio between the chromatographic areas of azelaic and palmitic acids (A/P value) and the sum of the chromatographic areas of the aliphatic dicarboxylic acids expressed as a percentage $(\Sigma \mathrm{D} \%)$ [36]. These values for the samples containing an amount of lipid material above the LOQ are shown in Additional file 1: Table S1, and an example of a chromatographic profile of the fatty acid content is shown in
Fig. 8 a. The A/P value is usually $>1$ and the $\Sigma \mathrm{D} \%>40 \%$ in siccative oils [36], but all the samples investigated showed lower values, which were more in agreement with a nonsiccative lipid binder or with the lipid components of egg (whole or yolk). Regarding sample 4_black and all the samples from object 5 , a very high value of the palmitic/ stearic $(\mathrm{P} / \mathrm{S})$ ratio (ca. 4, Additional file 1: Table S1) was interesting to notice. This is a parameter generally used to differentiate among oils $[9,61]$ and such high value has sometimes been considered indicative of perilla oil [7, 9]. Regarding object 3, a lipid material was detected on the basis of the presence of azelaic acid in the pyrograms, but GC-MS analysis was not possible for this object, therefore no further considerations can be made.

Some pyrolytic markers for proteins were detected in samples 1_green, 1_yellow and in all samples from object 6 , in particular pyrrole $(\mathrm{m} / z 67)$, methyl-pyrrole $(\mathrm{m} / \mathrm{z} 81)$ and pyridine $(\mathrm{m} / z$ 79) [34]. Octadecanenitrile was also identified in sample 4_black and is considered a marker for the presence of yolk or whole egg [34], although the role of egg is difficult to hypothesise, as this was not a coloured sample. GC-MS analysis revealed the presence of proteins in samples 1_green, 1_yellow, 2_red, 2_green, 2_yellow, 2_pink, 5_red, 6_red and 6_orange. Nevertheless, the amount of proteinaceous material in samples 1_green, 2_red, 2_green, 2_yellow, 5_red and 6_red was between the LOD and LOQ of the procedure, resulting in the identification of the protein source being analytically impossible. By contrast, in the case of samples 1_yellow, 2_pink and 6_orange, the protein content was above the LOQ of the procedure, thus enabling a semi-quantitative analysis of the data and the statistical treatment (PCA) 


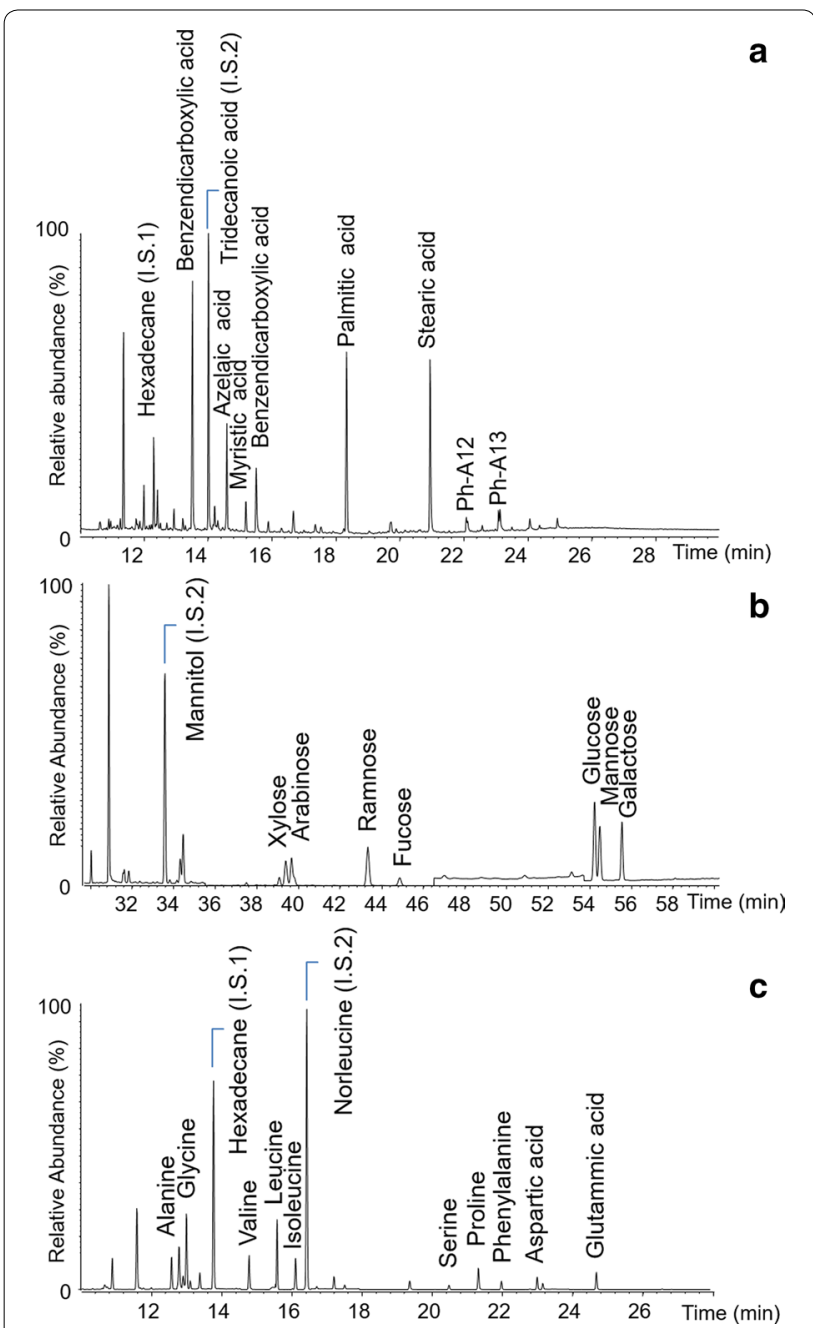

Fig. 8 a Total ion chromatogram of the lipid-resinous fraction of sample 6_red; $\mathbf{b}$ chromatogram obtained in the single ion monitoring mode of the saccharide fraction of sample 1_green; $\mathbf{c}$ chromatogram obtained in the single ion monitoring mode of the amino acidic fraction of sample 2_pink. I.S.1 = internal standard for injection; I.S.2 = internal standard for derivatisation

of the relative amino acid percentage content to be performed, as described in "Experimental section". The relative amino acid percentage content for these samples is shown in Additional file 1: Table S2, and an example of a chromatographic profile of the amino acid content is shown in Fig. 8c. The results of the PCA (Fig. 9) highlighted that sample 1_yellow and 6_orange are located close to the egg cluster, suggesting the presence of egg as binder. However, a shift towards lower values of the first principal component (PC1), and therefore towards the animal glue cluster, may suggest the presence of animal glue as well. This is also supported by the presence of hydroxyproline in the amino acidic profile of these

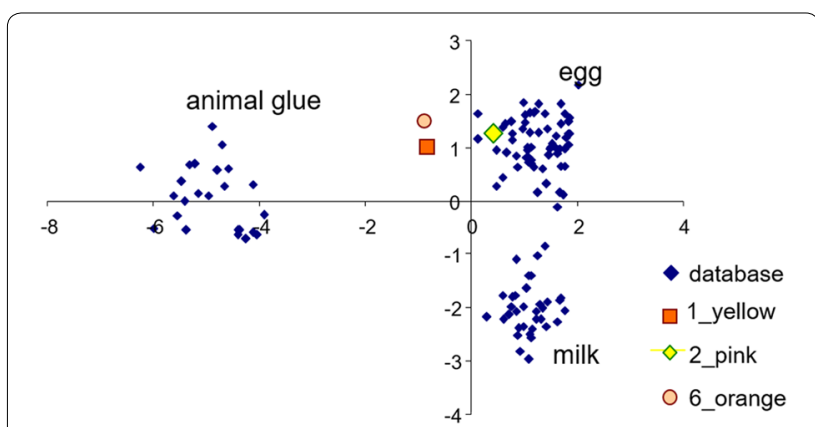

Fig. 9 Score plot of the PCA treatment (PC1 on the abscissa and PC2 on the ordinate) of the samples analysed. The first two components accounted for $96 \%$ of the total variance of data

samples, which is considered a marker for animal glue $[43,44]$. Hydroxyproline was also found in all the other samples showing a content of proteins below the LOQ. Sample 2_pink, instead, was well located in the egg cluster (Fig. 9).

The GC-MS analysis of sample 1_green revealed the presence of some saccharide material. The profile, shown in Fig. 8b, is not in agreement with any source present in the literature [46], but further considerations are presented in "Discussion" section. Samples 4_red and 4 green also showed the presence of a saccharide material. The saccharide profiles of the samples showed the presence of mannose and galactose that allows us to hypothesise the use of a gum, such as locust bean or guar gum [46].

Finally, the pyrogram of sample 6_orange was actually dominated by peaks attributed to phthalates. These are usually indicative of an alkyd resin, which could have been used as a previous treatment, but no record is available.

\section{Discussion}

The results led to new insights about the materials used in this traditional decorative technique. The use of cinnabar/vermillion and arsenic sulfide pigments, which were present in all the corresponding red and yellow areas of the objects investigated, is in agreement with historical records $[1,4,5]$. Nevertheless, evidence of production of amorphous arsenic sulfide by sublimation of natural orpiment was found [50,51,62], indicating that natural orpiment was not the only arsenic sulfide pigment used. Moreover, green is usually reported to be a mixture of orpiment and indigo (Table 1), but no indigo was found in the green areas of these objects. By contrast, Prussian blue was identified in a mixture with natural orpiment and/or amorphous arsenic sulfide. As Prussian blue has been available since the beginning of the eighteenth 

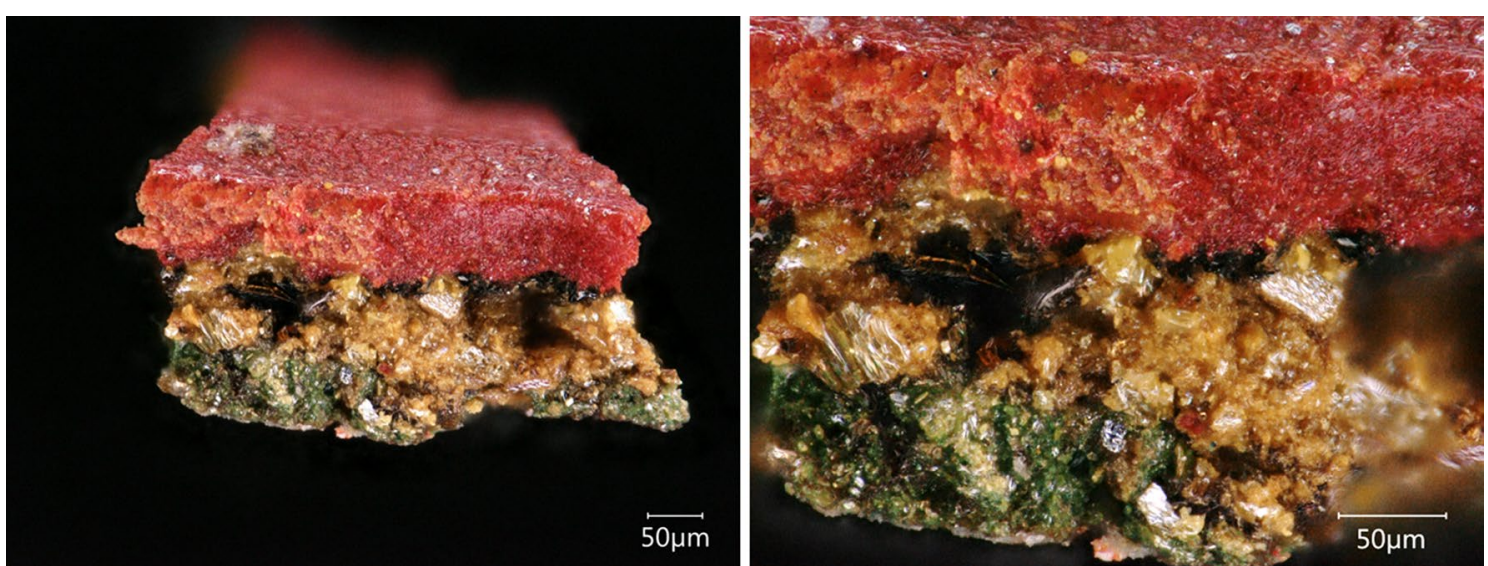

Fig. 10 Images obtained by digital microscopy at different magnifications of a sample taken from a red area of object 2, showing the stratigraphy of the paint layers

century [63], its presence is in line with the date of these objects, highlighting the availability of the pigment in Myanmar at least from the beginning of the nineteenth century. It has also been found in Japanese lacquerware from the late nineteenth century [11]. A completely different green formulation was found in the modern plates (object 1, late twentieth century), where phthalocyanine green, phthalocyanine blue and chrome yellow were identified, showing the integration of modern synthetic pigments in this traditional decorative technique. At least one other example of phthalocyanine blue is reported in twentieth century Vietnamese lacquerware [11] and some reference to mass-produced chemical colours appear in written records (Table 1).

Another discrepancy between literature and evidence collected during this study was revealed by a sample from object 2 that accidentally contained multiple paint layers (Fig. 10). This sample allowed the study of the stratigraphy by digital microscopy without the need to prepare an embedded cross section. In fact, although useful for interpreting the distribution of materials in lacquerware [7], cross sections were avoided in this work mainly to minimise the number of samples taken and because the series of nine plates (object 1 ) represents a deconstructed cross section in itself. While clearly showing the three traditional colours applied, the sample shown in Fig. 10 revealed that the traditional order of application was not respected in this case, as red is applied on the top of yellow and green layers, whereas red, green and then yellow is the order traditionally reported $[1,4,5]$.

In terms of the techniques adopted for the identification of the pigments used, this work shows that the noninvasive FORS can provide valuable information about the pigments. However, the correct interpretation of pigment mixtures is not always straightforward and yellow colourants do not always produce useful spectra. For example, most green would have been wrongly identified as Hooker's green (Prussian blue and gamboge) based on the FORS spectra. On the other hand, Raman spectroscopy offers the possibility to target single particles and therefore identify mixtures of pigments with high accuracy. However, samples have to be taken in order to reduce the interference related to the background fluorescence [11].

The analysis of the lacquer by Py(HMDS)-GC-MS resulted in the novel formulation of two parameters, such as the $\omega \mathrm{CT} / \mathrm{CT}$ ratio and the $\mathrm{K} / \mathrm{B}$ ratio, which are related to the oxidative degradation of the lacquer. Clear trends correlated oxidative degradation with the age of the objects, establishing a direct line between the two. Nevertheless, the fact that the two trends are not completely specular suggests that age is not the only parameter involved in lacquer degradation processes. Photo-oxidation is reported to justify lacquer degradation [9], but the actual contribution of this phenomenon is difficult to predict if the exact history of the objects is not known. On the other hand, it has been demonstrated that the addition of siccative oil to lacquer hastens the oxidation of the lacquer, as a radical-rich environment is created $[8,14]$. These observations suggest that more research is needed to pin down the causes of Burmese lacquer degradation, although a simple contribution from natural ageing appears evident.

Regarding the other organic materials, the results showed a variety of binding media/additives/adhesives being in these objects. In terms of additives, siccative oils are most frequently mentioned in the literature, in particular tung, perilla, sesame and peanut oils $[1,4,5$, 7]. However, the results of this study were more consistent with the presence of semi-siccative/non-siccative 
lipids. A reason for this might be that the autoxidative process of drying oils is affected by the presence of lacquer, resulting in a drastic decrease in the $\mathrm{A} / \mathrm{P}$ and $\Sigma \mathrm{D} \%$ values compared to values of oils that cure on their own [14]. Although this has only been ascertained for mixtures of urushi and tung oil, it is reasonable to believe that other drying oils and Burmese lacquer behave similarly. This makes the $\mathrm{A} / \mathrm{P}$ and $\Sigma \mathrm{D} \%$ values less reliable in these systems and the presence of siccative oil cannot be completely excluded. As an additional complication, the presence of egg, which was identified in a few cases, is known to alter the lipid profile, making the $\mathrm{A} / \mathrm{P}$ and $\Sigma \mathrm{D} \%$ values even more unreliable.

Vegetable gums are also reported and their use appears to be related to sealing a layer before applying the next one $[1,4,5]$. Saccharides were detected in four out of the six objects, in either the red or green samples. The identification of the gum source was not straightforward. In one case (sample 1_green) tragacanth gum was suspected due to the presence of fucose, which is considered a marker of this gum [46], but the gum from the neem/ tama tree (Azadirachta indica) is often mentioned and contains traces of xylose, arabinose, fucose, glucuronic acid and galactose [64]. A reference sample of this gum was not available and the saccharide profile of sample $1_{-}$ green is not in complete agreement with the reference in the literature [64]. However, studies on the artificial ageing of paint layers containing pigments showed that both qualitative and quantitative changes occur in the saccharide composition depending on the ageing conditions and the pigment present [46].

Proteins are not explicitly mentioned as materials used in the yun technique (Table 1), but "secret ingredients" are often mentioned, whose nature was not shared with foreigners [1, 4-6]. Nevertheless, proteins were identified in several samples (four out of six objects) and the results pointed towards egg or animal glue as possible sources. The identification was made on the basis of a database that considers the most common proteinaceous materials in the European tradition (egg, milk and animal glue). Materials from South East Asia should be considered, but their amino acidic profile is not available in the literature. However, Asian polychrome objects studied in the literature show that the materials used by the Asian artists are mainly egg, milk and animal glue [65-67], as confirmed in some cases by the use of proteomics. The risk of contamination is difficult to rule out: the use of bare hands to apply materials is reported, as well as spittle used in the thayo. Moreover, no precise records of conservation treatments are available and these could represent a source of animal glue, although care was taken to sample in areas that appeared original.

\section{Conclusions}

This study presents the first systematic investigation of a selection of Burmese lacquered objects decorated with the $y u n$ technique and the first application of a multianalytical approach based on digital microscopy, FORS, Raman, GC-MS and Py(HMDS)-GC-MS to such objects.

The results of this study shed new light on the materials traditionally used for this decorative technique and, when compared with the written records, new findings were highlighted, such as the use of Prussian blue instead of indigo to be mixed with yellow (natural or artificial orpiment) in green pigment formulations. Other synthetic pigments have been found on modern objects, such as chrome yellow and phthalocyanine blue and green, highlighting an evolution of the materials. Further exploring pigment production/technology, including the difference between mineral cinnabar and synthetic vermillion, natural and synthetic orpiment, and use of Prussian blue, promises to be an interesting avenue for future research.

A special focus has been the identification of organic materials usually mixed with Burmese lacquer. Interesting mixtures of proteins, lipids and vegetable gums were detected and, although the identification was not unequivocal in most cases, it appeared that these materials were specifically used with certain pigments. Other analytical techniques, such as MS-based proteomics and lipidomics or MALDI-ToF analysis might be useful in the future to better identify the natural sources of these materials.

These findings also represent an important source of information for conservators entrusted with the care of these objects. Characterisation of materials enables the formulation of appropriate collections care strategies, can explain deterioration patterns, and provides guidance for planning interventive conservation treatments. For example, the confirmation of orpiment as a yellow colourant is valuable as this pigment is prone to fading. Additionally, a better understanding of the components in Burmese lacquerware lays the foundations for future comparisons among the varying lacquer traditions within the country and with lacquer forms from regions surrounding it. Since the lacquer traditions in the region can share stylistic features, analyses of materials will augment knowledge of the extent of cross-cultural exchanges and the movement of information and objects over time.

Finally, future research should focus on the interactions among these materials. Lacquer, lipids, proteins, gums and pigments constitute extremely complex systems, which sometimes evolve in time in unexpected ways, and information about the actual stability of these systems would further help the preservation of these precious objects. 


\section{Additional file}

Additional file 1. Figure S1. Series of plates illustrating the yun process. a) Application of raw lacquer (the plate is from the same workshop but not from the same production as the others); b) application of refined lacquer; c) carving and application of red lacquer; $\mathbf{d}$ ) application of green lacquer; e) application of yellow lacquer; f) finished product. Images obtained by digital microscopy of samples $\mathbf{g}) 1 \mathrm{c}, \mathbf{h}) 1 \mathrm{~d}$ and i) 1e. Figure S2. A rectangular wooden tray (object 2) produced in the 1920s using the yun technique (length $56 \mathrm{~cm}$; width $37 \mathrm{~cm}$ ) and sampling areas of a) yellow, b) red, c) green and d) pink colours (scale bar $1 \mathrm{~mm}$ ). Images obtained by digital microscopy of the corresponding samples $\mathbf{a}^{\prime}$ ) 2d, $\left.\mathbf{b}^{\prime}\right) 2 \mathrm{~b} \mathbf{c}^{\prime}$ ) 2c and $\mathbf{d}^{\prime}$ ) 2e. Figure S3. A betel box (object 3) produced in the early 20th century using the yun technique (height $15 \mathrm{~cm}$; diameter $19.2 \mathrm{~cm}$ ) and sampling areas of a) black and b) red colours (scale bar in $1 \mathrm{~mm}$ ). Images obtained at different magnifications by digital microscopy of sample 3b (c and d). Figure S4. A bowl (object 4) produced in the mid-late 19th century using the yun technique (height $18.8 \mathrm{~cm}$; diameter $23.8 \mathrm{~cm}$ ) and sampling areas of a) green, b) yellow and c) red colours (scale bar in $1 \mathrm{~mm}$ ). Images obtained by digital microscopy of the corresponding samples $\mathbf{a}^{\prime}$ ) 4c, b') $4 d$ and $\mathbf{c}^{\prime}$ ) $4 b$. Figure S5. A coffer (object 5) produced in the early 19th century using the yun technique (height $16.5 \mathrm{~cm}$; width $22 \mathrm{~cm}$; length $39 \mathrm{~cm}$ ) and sampling areas of a) red, b) yellow and c) green colours (scale bar in $1 \mathrm{~mm}$ ). Images obtained by digital microscopy of the corresponding samples $\mathbf{a}^{\prime}$ ) 5b, b') $5 d$ and $\mathbf{c}^{\prime}$ ) 5c. Figure S6. A box (object 6) produced in the early 19th century using the yun technique (height $24 \mathrm{~cm}$; diameter $37 \mathrm{~cm}$ ) and sampling areas of a) red and b) orange colours (scale bar in $1 \mathrm{~mm}$ ). Images obtained by digital microscopy of the corresponding samples $\mathbf{a}^{\prime}$ ) $3 \mathrm{~b}$ and $\mathbf{b}^{\prime}$ ) $3 \mathrm{c}$. Figure S7. Chromatographic profiles obtained by Py(HMDS)-GC-MS of a) sample 1_red (extract ion chromatogram of the ion with $\mathrm{m} / \mathrm{z} 202$ for mercury) and $\mathbf{b}$ ) sample 2_green (extract ion chromatogram of the ion with $\mathrm{m} / \mathrm{z} 207$ for arsenic and sulphur compounds). Table S1. Typical values obtained from the relative fatty acid percentage content of the samples and total amount of lipid material quantified ( $\mu \mathrm{g}$ tot). A/P: azelaic/ palmitic; P/S: palmitic/stearic; O/S: oleic/stearic; $\Sigma D(\%)$ : sum of dicarboxylic acids. Table S2. Relative amino acid percentage content of the samples and total amount of proteinaceous material quantified ( $\mu \mathrm{g}$ tot). Ala: alanine; Gly: glycine; Val: valine; Leu: leucine; lle: isoleucine; Ser: serine; Pro: proline; Phe: phenylalanine; Asp: aspartic acid; Glu: glutamic acid; Hyp: hydroxyproline.

\section{Acknowledgements}

The authors would like to thank Dr. Joanne Dyer, Dr. Lucia Burgio and Dr. Marc Vermeulen for helping with the interpretation of some Raman spectra. As an Andrew W. Mellon Postdoctoral Research Fellow, Diego Tamburini would also like to thank the Andrew W. Mellon foundation.

\section{Authors' contributions}

DT was responsible for the conception and design of the work, acquisition and interpretation of data and drafting the paper. VK contributed to the acquisition of data, drafting the paper and substantively revised it. ALT contributed to the acquisition and interpretation of data, drafting the paper and substantively revised it. MPC and AG contributed to the interpretation of data and substantively revised the paper. All authors read and approved the final manuscript.

\section{Funding}

Not applicable

\section{Availability of data and materials}

The datasets used and/or analysed during the current study are available from the corresponding author on reasonable request.

\section{Competing interests}

The authors declare that they have no competing interests.

\section{Author details}

${ }^{1}$ Department of Scientific Research, The British Museum, Great Russell Street, London WC1B 3DG, UK. ${ }^{2}$ Department of Conservation, The British Museum, Great Russell Street, London WC1B 3DG, UK. ${ }^{3}$ Department of Chemistry and Industrial Chemistry, University of Pisa, via Giuseppe Moruzzi 13, 56124 Pisa, Italy. ${ }^{4}$ Department of Asia, The British Museum, Great Russell Street, London WC1B 3DG, UK.

Received: 13 February 2019 Accepted: 30 April 2019

Published online: 08 May 2019

\section{References}

1. Isaacs R, Blurton TR. Visions from the golden land: Burma and the art of lacquer. London: British Museum; 2000.

2. Singer NF. Burmese dance and theatre. Oxford: Oxford University Press; 1996.

3. Weigelt U. Birmas Lackkunst in deutschen Museen (German). Münster: Museum für Lackkunst; 2005.

4. Fraser-Lu S. Burmese Lacquerware. White orchid books. Weatherhill; Revised, Expanded edition (2000); 2000.

5. Than H. Lacquerware journeys: the untold story of Burmese lacquer/Than Htun (Dedaye); editor: Narisa Chakrabongse; additional photography: Paisarn Piemmattawat. Bangkok: River Books; 2013. https://nla.gov.au/nla. cat-vn6294466. Accessed Jan 2019

6. Burney H. Some account of the lacquered or japanned ware of Ava. J Asiatic Soc Bengal. 1832;1(5):169-87.

7. Risdonne V, Burgio L, Schilling MR, Khanjian H. Investigation of Burmese lacquer methods: technical examination of the V\&A Burmese shrine. J Cult Herit. 2018;30:16-25. https://doi.org/10.1016/j.culher.2017.07.003.

8. Tamburini D, Pescitelli G, Colombini MP, Bonaduce I. The degradation of Burmese lacquer (thitsi) as observed in samples from two cultural artefacts. J Anal Appl Pyrol. 2017;124:51-62. https://doi.org/10.1016/j. jaap.2017.02.023.

9. Schilling MR, Heginbotham A, van Keulen H, Szelewski M. Beyond the basics: a systematic approach for comprehensive analysis of organic materials in Asian lacquers. Stud Conserv. 2016;61(sup3):3-27. https://doi. org/10.1080/00393630.2016.1230978.

10. Minney F. The conservation of a Burmese dry lacquer statue of Buddha. Stud Conserv. 1994;39(3):154-60. https://doi.org/10.2307/1506594.

11. Colomban P, Mancini D. Lacquerware pigment identification with fixed and mobile raman microspectrometers: a potential technique to differentiate original/fake artworks. Arts. 2013;2(3):111

12. Hao X, Wu H, Zhao Y, Tong T, Li X, Yang C, et al. Analysis on the composition/structure and lacquering techniques of the coffin of emperor qianlong excavated from the eastern imperial tombs. Scientific Rep. 2017;7(1):8446. https://doi.org/10.1038/s41598-017-08933-8.

13. Kamiya Y, Honda T, Ohbuchi A, Miyakoshi T. Simultaneous organic and inorganic analysis of colored oriental lacquerware by pyrolysis-gas chromatography/mass spectrometry. Int J Polym Sci. 2015;2015:11. https ://doi.org/10.1155/2015/725467.

14. Tamburini D, Sardi D, Spepi A, Duce C, Tinè MR, Colombini MP, et al. An investigation into the curing of urushi and tung oil films by thermoanalytical and mass spectrometric techniques. Polym Degrad Stab. 2016;134:251-64. https://doi.org/10.1016/j.polymdegradstab.2016.10.015.

15. Higgitt C, Spring M, Saunders D. Pigment-medium interactions in oil paint films containing red lead or lead-tin yellow. Natl Gallery Tech Bull. 2003;24:75-95.

16. Lu R, Yoshida T, Miyakoshi T. Oriental lacquer: a natural polymer. Polym Rev. 2013;53(2):153-91. https://doi.org/10.1080/15583724.2013.776585.

17. Honda T, Lu R, Sakai R, Ishimura T, Miyakoshi T. Characterization and comparison of Asian lacquer saps. Prog Org Coat. 2008;61(1):68-75. https ://doi.org/10.1016/j.porgcoat.2007.09.003.

18. Lu R, Kamiya Y, Miyakoshi T. Characterization of lipid components of Melanorrhoea usitata lacquer sap. Talanta. 2007;71:1536-40. 
19. Lu R, Kamiya Y, Miyakoshi T. Preparation and characterization of Melanorrhoea usitata lacquer film based on pyrolysis-gas chromatography/ mass spectrometry. J Anal Appl Pyrol. 2007;78(1):172-9. https://doi. org/10.1016/j.jaap.2006.06.006.

20. Tamburini D, Bonaduce I, Colombini MP. Characterisation of oriental lacquers from Rhus succedanea and Melanorrhoea usitata using in situ pyrolysis/silylation-gas chromatography mass spectrometry. J Anal Appl Pyrol. 2015;116:129-41. https://doi.org/10.1016/j.jaap.2015.09.017.

21. Yuasa K, Honda T, Lu R, Hachiya T, Miyakoshi T. Analysis of Japanese ancient lacquerwares excavated from Jōmon period ruins. J Anal Appl Pyrol. 2015;113:73-7. https://doi.org/10.1016/j.jaap.2014.10.018.

22. Honda T, Lu R, Yamabuki M, Ando D, Miyazato M, Yoshida K, et al. Investigation of Ryukyu lacquerwares by pyrolysis-gas chromatography/mass spectrometry. J Anal Appl Pyrol. 2015;113:41-5. https://doi.org/10.1016/j. jaap.2014.09.026.

23. Pitthard V, Wei S, Miklin-Kniefacz S, Stanek S, Griesser M, Schreiner M. Scientific investigations of antique lacquers fron a 17th-century japanese ornamental cabinet. Archaeometry. 2010;52(6):1044-56.

24. Frade JC, Ribeiro I, Graça J, Vasconcelos T, Rodrigues J. Chemotaxonomic application of Py-GC/MS: identification of lacquer trees. J Anal Appl Pyrol. 2010;89(1):117-21. https://doi.org/10.1016/j.jaap.2010.06.006.

25. Niimura N. Determination of the type of lacquer on East Asian lacquer ware. Int J Mass Spectrom. 2009;284:93-7.

26. Mazzeo R, Cam D, Chiavari G, Fabbri D, Ling H, Prati S. Analytical study of traditional decorative materials and techniques used in Ming Dinasty wooden architecture. The case of the Drum Tower in Xi'an, P.R of China. J Cult Herit. 2004;5:273-83.

27. Takahashi S, Sung M, Honda T, Lu R, Jung J, Miyakoshi T. Analysis of Japanese Jōmon period red lacquerwares by pyrolysis gas chromatography/mass spectrometry. J Archaeol Sci Rep. 2018;18:85-9. https://doi. org/10.1016/j.jasrep.2018.01.013.

28. Wei S, Pintus V, Pitthard V, Schreiner M, Guoding Song G. Analytical characterization of lacquer objects excavated from a Chu tomb in China. J Archaeol Sci. 2011;38:2667-74.

29. Le Hô A, Regert M, Marescota O, Duhamela C, Langloisa J, Miyakoshi T, et al. Molecular criteria for discriminating museum Asian lacquerware from different vegetal origins by pyrolysis gas chromatography/mass spectrometry. Anal Chim Acta. 2012;710:9-16.

30. Heginbotham A, Schilling M. New evidence for the use of Southeast Asian raw materials in seventeenth-century Japanese export lacquer. In: Shayne Rivers RFaBP, editor. East Asian lacquer: material culture, science and conservation. London: Archetype Publications; 2011. p. 92-106.

31. Ling H, Maiqian N, Chiavari G, Mazzeo R. Analytical characterization of binding medium used in ancient Chinese artworks by pyrolysis-gas chromatography/mass spectrometry. Microchem J. 2007;85(2):347-53. https://doi.org/10.1016/j.microc.2006.08.003.

32. Tamburini D, Bonaduce I, Colombini MP. Characterization and identification of urushi using in situ pyrolysis/silylation-gas chromatography-mass spectrometry. J Anal Appl Pyrol. 2015;111:33-40. https://doi. org/10.1016/j.jaap.2014.12.018.

33. Degano I, Modugno F, Bonaduce I, Ribechini E, Colombini MP. Recent advances in analytical pyrolysis to investigate organic materials in heritage science. Angew Chem Int Ed. 2018;57(25):7313-23. https://doi. org/10.1002/anie.201713404.

34. Bonaduce I, Andreotti A. Py-GC/MS of organic paint binders. In: Colombini MP, Modugno F, editors. Organic mass spectrometry in art and archeology. Chichester: Wiley; 2009. p. 303-26.

35. Colombini MP, Andreotti A, Bonaduce I, Modugno F, Ribechini E. Analytical strategies for characterizing organic paint media using gas chromatography/mass spectrometry. Acc Chem Res. 2010;43(6):715-27. https:// doi.org/10.1021/ar900185f.

36. Bonaduce I, Ribechini E, Modugno F, Colombini MP. Analytical approaches based on gas chromatography mass spectrometry (GC/MS) to study organic materials in artworks and archaeological objects. Top Curr Chem. 2016;374(1):6. https://doi.org/10.1007/s41061-015-0007-x.

37. Vinciguerra R, De Chiaro A, Pucci P, Marino G, Birolo L. Proteomic strategies for cultural heritage: from bones to paintings. Microchem J. 2016;126:341-8. https://doi.org/10.1016/j.microc.2015.12.024.

38. Degano I, La Nasa J. Trends in high performance liquid chromatography for cultural heritage. Top Curr Chem. 2016;374(2):1-28. https://doi. org/10.1007/s41061-016-0020-8.
39. Bersani D, Conti C, Matousek P, Pozzi F, Vandenabeele P. Methodological evolutions of Raman spectroscopy in art and archaeology. Anal Methods. 2016;8(48):8395-409. https://doi.org/10.1039/c6ay02327d.

40. Burgio L, Clark RJH. Library of FT-Raman spectra of pigments, minerals, pigment media and varnishes, and supplement to existing library of Raman spectra of pigments with visible excitation. Spectrochim Acta Part A Mol Biomol Spectrosc. 2001;57(7):1491-521. https://doi.org/10.1016/ S1386-1425(00)00495-9.

41. Aceto M, Agostino A, Fenoglio G, Idone A, Gulmini M, Picollo M, et al. Characterisation of colourants on illuminated manuscripts by portable fibre optic UV-visible-NIR reflectance spectrophotometry. Anal Methods. 2014;6(5):1488-500. https://doi.org/10.1039/c3ay41904e.

42. Lluveras A, Bonaduce I, Andreotti A, Colombini MP. GC/MS analytical procedure for the characterization of glycerolipids, natural waxes, terpenoid resins, proteinaceous and polysaccharide materials in the same paint microsample avoiding interferences from inorganic media. Anal Chem. 2010;82(1):376-86.

43. Colombini MP, Modugno F. Characterisation of proteinaceous binders in artistic paintings by chromatographic techniques. J Sep Sci. 2004;27(3):147-60. https://doi.org/10.1002/jssc.200301625.

44. Colombini MP, Modugno F, Menicagli E, Fuoco R, Giacomelli A. GC-MS characterization of proteinaceous and lipid binders in UV aged polychrome artifacts. Microchem J. 2000;67(1):291-300. https://doi. org/10.1016/S0026-265X(00)00075-8.

45. Bonaduce I, Brecoulaki H, Colombini MP, Lluveras A, Restivo V, Ribechini E. Gas chromatographic-mass spectrometric characterisation of plant gums in samples from painted works of art. J Chromatogr A. 2007;1175(2):275-82. https://doi.org/10.1016/j.chroma.2007.10.056.

46. Lluveras-Tenorio A, Mazurek J, Restivo A, Colombini MP, Bonaduce I. The development of a new analytical model for the identification of saccharide binders in paint samples. PLoS ONE. 2012;7(11):e49383. https://doi. org/10.1371/journal.pone.0049383.

47. Cosentino A. FORS spectral database of historical pigments in different binders. e-conserv J. 2014;53:65. https://doi.org/10.18236/econs2.201410.

48. Gettens RJ, Feller RL, Chase WT. Vermilion and cinnabar. Stud Conserv. 1972;17(2):45-69. https://doi.org/10.2307/1505572.

49. Chiavari G, Mazzeo R. Characterisation of paint layers in Chinese archaelogical relics by pyrolysis-GC-MS. Chromatographia. 1999;49(5):268-72. https://doi.org/10.1007/bf02467555.

50. Vermeulen M, Saverwyns S, Coudray A, Janssens K, Sanyova J. Identification by Raman spectroscopy of pararealgar as a starting material in the synthesis of amorphous arsenic sulfide pigments. Dyes Pigm. 2018;149:290-7. https://doi.org/10.1016/j.dyepig.2017.10.009.

51. Vermeulen M, Palka K, Vlček M, Sanyova J. Study of dry- and wetprocess amorphous arsenic sulfides: synthesis, Raman reference spectra, and identification in historical art materials. J Raman Spectrosc. 2019;50(3):396-406. https://doi.org/10.1002/jrs.5534.

52. Chiavari G, Fabbri D, Galletti GC. Pyrolysis/gas chromatography/mass spectrometry of arsenic inorganic compounds. Rapid Commun Mass Spectrom. 1995;9(7):559-62. https://doi.org/10.1002/rcm.1290090703.

53. Poldi G, Caglio S. Phthalocyanine identification in paintings by reflectance spectroscopy. A laboratory and in situ study. Opt Spectrosc. 2013;114(6):929-35. https://doi.org/10.1134/s0030400x13060143.

54. Monico L, Janssens K, Hendriks E, Brunetti BG, Miliani C. Raman study of different crystalline forms of $\mathrm{PbCrO} 4$ and $\mathrm{PbCr} 1-x \mathrm{SxO} 4$ solid solutions for the noninvasive identification of chrome yellows in paintings: a focus on works by Vincent van Gogh. J Raman Spectrosc. 2014;45(11-12):103445. https://doi.org/10.1002/jrs.4548.

55. Riddle JW, Hopkins EJ, Butler IS. Variable-temperature micro-raman spectra of the synthetic artists' pigments, chrome yellow and maya blue: an undergraduate research project. Spectrosc Lett. 2015;48(8):556-60. https ://doi.org/10.1080/00387010.2014.924529.

56. Defeyt C, Vandenabeele P, Gilbert B, Van Pevenage J, Cloots R, Strivay D. Contribution to the identification of $\alpha-, \beta$ - and $\varepsilon$-copper phthalocyanine blue pigments in modern artists' paints by $X$-ray powder diffraction, attenuated total reflectance micro-fourier transform infrared spectroscopy and micro-Raman spectroscopy. J Raman Spectrosc. 2012;43(11):1772-80. https://doi.org/10.1002/jrs.4125.

57. Schulte F, Brzezinka K-W, Lutzenberger K, Stege H, Panne U. Raman spectroscopy of synthetic organic pigments used in 20th century works 
of art. J Raman Spectrosc. 2008;39(10):1455-63. https://doi.org/10.1002/ jrs.2021.

58. Johnston-Feller R. Color science in the examination of museum objects: nondestructive procedures. Tools for conservation. Los Angeles: Getty Conservation Institute; 2001

59. Germinario G, Werf IDVD, Sabbatini L. Pyrolysis gas chromatography mass spectrometry of two green phthalocyanine pigments and their identification in paint systems. J Anal Appl Pyrolysis. 2015;115:175-83. https:// doi.org/10.1016/j.jaap.2015.07.016

60. Theodorakopoulos C, Boon JJ, Zafiropulos V. Direct temperature mass spectrometric study on the depth-dependent compositional gradients of aged triterpenoid varnishes. Int J Mass Spectrom. 2009;284(1):98-107. https://doi.org/10.1016/j.ijms.2008.11.004.

61. Colombini MP, Modugno F, Ribechini E. GC/MS in the characterization of lipids. In: Colombini MP, Modugno F, editors. Organic mass spectrometry in art and archeology. Chichester: Wiley; 2009. p. 191-213.

62. Vermeulen M, Nuyts G, Sanyova J, Vila A, Buti D, Suuronen J-P, et al. Visualization of $\mathrm{As}$ (iii) and $\mathrm{As}(\mathrm{V})$ distributions in degraded paint microsamples from Baroque- and Rococo-era paintings. J Anal At Spectrom. 2016:31(9):1913-21. https://doi.org/10.1039/c6ja00134c.

63. Eastaugh N. Pigment compendium: a dictionary and optical microscopy of historical pigments. Amsterdam: Butterworth-Heinemann; 2008.
64. Mukherjee S, Srivastava HC. The structure of neem gum. J Am Chem Soc. 1955;77(2):422-3. https://doi.org/10.1021/ja01607a059.

65. Bonaduce I, Blaensdorf C, Dietemann P, Colombini MP. The binding media of the polychromy of Qin Shihuang'Terracotta Army. J Cult Herit. 2008;9:103-8.

66. Lluveras-Tenorio A, Vinciguerra R, Galano E, Blaensdorf C, Emmerling E, Perla Colombini M, et al. GC/MS and proteomics to unravel the painting history of the lost Giant Buddhas of Bāmiyān (Afghanistan). PLoS ONE. 2017;12(4):e0172990. https://doi.org/10.1371/journal.pone.0172990.

67. Lluveras-Tenorio A, Bonaduce I, Sabatini F, Degano I, Blaensdorf C, Pouyet $\mathrm{E}$, et al. The organic materials in the Five Northern Provinces' Assembly Hall: disclosing the painting technique of the Qing dynasty painters in civil buildings. Appl Phys A. 2015;121(3):879-89. https://doi.org/10.1007/ s00339-015-9362-2

\section{Publisher's Note}

Springer Nature remains neutral with regard to jurisdictional claims in published maps and institutional affiliations.

\section{Submit your manuscript to a SpringerOpen ${ }^{\circ}$ journal and benefit from:}

- Convenient online submission

- Rigorous peer review

- Open access: articles freely available online

- High visibility within the field

- Retaining the copyright to your article

Submit your next manuscript at $\boldsymbol{\nabla}$ springeropen.com 